\title{
Univariate and multivariate control charts for monitoring dynamic-behavior processes: a case study
}

\author{
Salah Haridy, Zhang Wu \\ School of Mechanical and Aerospace Engineering, Nanyang Technological University \\ (SINGAPORE) \\ salab@pmail.ntu.edu.sg; mswn@,ntu.edu.sg
}

Received August 2009

Accepted December 2009

\begin{abstract}
The majority of classic SPC methodologies assume a steady-state (i.e., static) process behavior (i.e., the process mean and variance are constant) without the influence of the dynamic behavior (i.e., an intended or unintended shift in the process mean or variance). Traditional SPC has been successfully used in steady-state manufacturing processes, but these approaches are not valid for use in dynamic behavior environments. The goal of this paper is to present the process monitoring and adjustment methodologies for addressing dynamic behavior problems so that system performance improvement may be attained. The methodologies will provide a scientific approach to acquire critical knowledge of the dynamic behavior as well as improved control and quality, leading to the enhancement of economic position. The two major developments in this paper are: (1) the characterization of the dynamic behavior of the manufacturing process with the appropriate monitoring procedures; and (2) the development of adaptive monitoring procedures for the processes [for example, using trend charts (e.g., linear model) and time series charts (e.g., ARIMA models)] with a comparison between univariate and multivariate control charts. To provide a realistic environment for the development of the dynamic behavior monitoring and adjustment procedures, the cold rolling process is adopted as a test bed.
\end{abstract}


Keywords: statistical process control (SPC), dynamic behavior, EWMA control charts, MEWMA control chart, autocorrelation, ARIMA models, cold rolling, linear trend models

\section{Introduction}

Statistical process control (SPC) has played a major role in controlling the product quality for decades since Shewhart (1931) illustrated the technique of the control chart by applying statistical concepts in the manufacturing process. Driven by global competition and evolving customer needs and expectations, manufacturing systems today have witnessed a significant increase in dynamic behavior and unstable state (i.e., an attempt to shift the process from one operating level to another).

The majority of the body of SPC methodologies assume a steady-state process behavior, i.e., without the influence of the dynamic behavior (Grant \& Leavenworth, 1996; Box \& Luceno, 1997). Traditional SPC has been successfully used in the steady-state manufacturing processes, but recently these approaches are being reevaluated for use in the dynamic behavior environment. Quality control activities should not disturb the flow of the production process. That is, the way by which the process control approach collects, stores, analyzes and presents quality related information must cope with the nature of the process. Recently, the use of SPC methodologies to address the process that are in dynamic behavior mode has started to emerge.

The standard assumptions in SPC are that the observed process values are normally, independently and identically distributed (IID) with fixed mean $\mu$ and standard deviation $\sigma$ when the process is in control. Due to the dynamic behavior, these assumptions are not always valid. The data may not be normally distributed and/or autocorrelated, especially when the data are observed sequentially and the time between samples is short. The presence of autocorrelation has a significant effect on control charts developed using the assumption of independent observations. Alwan (1992) investigated the impact of autocorrelated data on the traditional Shewhart chart and reported an increased number of false alarms. Elsayed (2000) suggested that there is a tremendous need for improvement in the 
area of SPC in industries such as the food, chemical, automotive and manufacturing industries, given that these industries inherently deal with numerous variables which are highly correlated.

In many publications, various authors such as Coleman (1997) and Box and Luceno (1997) showed that normality cannot exist in practice. These authors stress that recent developments on control charts still have a "potential drawback" due to the fact "that they are based on the assumption of normal process data". Coleman (1997) strongly believes that in industry the normality assumption is unbelievable, therefore as he has stated "distribution-free SPC is what we need" to remove the normality assumption required in current methods.

In reality, manufacturing systems are often influenced by many known or unknown disturbances. The process means may even be subject to non-stationary drifts (Box \& Kramer, 1992). For the specific problem of dynamic behavior, Nembhard and Mastrangelo (1998) and Nembhard, Mastrangelo, and Kao (2001) proposed an integrated process control (IPC) technique that combines engineering process control (EPC) and SPC on noisy dynamic systems. There is a research topic that has targeted the detection of a linear trend using EWMA and CUSUM control charts (Bissell, 1984; Aerne, Champ, \& Rigdon, 1991). Ogunnaike and Ray (1994) proposed an additive stochastic disturbance assumption for the dynamic process. This assumption is widely used in modeling dynamic industrial processes.

A cold rolling process is an integral part of this paper because it (as most metal forming processes) undergoes many disturbances and dynamic behavior during the production, so it provides a real environment for the development of dynamic behavior monitoring and adjustment procedures. Some software packages such as MINITAB 14, Statgraphics Centurion XV, and SolidWorks 2007 were used in this work.

\section{Univariate control charts}

One major drawback of the Shewhart chart is that it considers only the last data point and does not carry a memory of the previous data. As a result, small changes in the mean of a random variable are less likely to be detected rapidly. Exponentially weighted moving average (EWMA) chart improves upon the detection of small process shifts. Rapid detection of small changes in the quality 
characteristic of interest and ease of computations through recursive equations are some of the many good properties of EWMA chart that make it attractive.

EWMA chart was first introduced by Roberts (1959) to achieve faster detection of small changes in the mean. The EWMA chart is used extensively in time series modeling and forecasting for processes with gradual drift (Box, Jenkins, \& Reinsel, 1994). It provides a forecast of where the process will be in the next instance of time. It thus provides a mechanism for dynamic process control (Hunter, 1986).

The Exponentially Weighted Moving Average (EWMA) is a statistic for monitoring the process that averages the data in a way that gives exponentially less and less weight to data as they are further removed in time. EWMA is defined as:

$$
Z_{i}=\lambda \overline{X_{i}}+(1-\lambda) Z_{i-1} \quad \text { with } 0 \leq \lambda<1, Z_{0}=\mu_{0}
$$

It can be used as the basis of a control chart. The procedure consists of plotting the EWMA statistic $Z_{i}$ versus the sample number on a control chart with center line $\mathrm{CL}=\mu_{0}$ and upper and lower control limits at

$$
\begin{aligned}
& U C L=\mu_{0}+k \sigma_{\bar{X}} \sqrt{\frac{\lambda}{2-\lambda}\left[1-(1-\lambda)^{2 i}\right]} \\
& L C L=\mu_{0}+k \sigma_{\bar{X}} \sqrt{\frac{\lambda}{2-\lambda}\left[1-(1-\lambda)^{2 i}\right]}
\end{aligned}
$$

The term [1- $\left.(1-\lambda)^{2 i}\right]$ approaches unity as i gets larger, so after several sampling intervals, the control limits will approach the steady state values

$$
\begin{gathered}
U C L=\mu_{0}+k \sigma_{\bar{X}} \sqrt{\frac{\lambda}{2-\lambda}} \\
L C L=\mu_{0}-k \sigma_{\bar{x}} \sqrt{\frac{\lambda}{2-\lambda}}
\end{gathered}
$$

The design parameters are the width of the control limits $k$ and the EWMA parameter $\lambda$. Montgomery (2005) gives a table of recommended values for these parameters to achieve certain average run length performance. 
Rather than basing control charts on ranges, a more modern approach for monitoring process variability is to calculate the standard deviation of each subgroup and use these values to monitor the process standard deviation $(\sigma)$. This is called an S chart. When an S chart is used, it is common to use these standard deviations to develop control limits for the control chart. Typically, the sample size used for subgroups is small (fewer than 10) and in that case there is usually little difference in the control charts generated from ranges or standard deviations. However, because computer software is often used to implement control charts, $\mathrm{S}$ charts are used quite commonly (Montgomery \& Runger, 2003)

Let the sample mean for the $\mathrm{i}^{\text {th }}$ sample be $\overline{X_{i}}$. Then we estimate the mean of the population $\mu$, by the grand mean

$$
\mu=\overline{\bar{X}}=\frac{1}{m} \sum_{i=1}^{m} \bar{X}_{i}
$$

Assume that there are $\mathrm{m}$ preliminary samples available, each of size $\mathrm{n}$, and let $S_{i}$ denote the standard deviation of the $\mathrm{i}^{\text {th }}$ sample. Define:

$$
\bar{S}=\frac{1}{m} \sum_{i=1}^{m} S_{i}
$$

Now, once we have computed the sample values $\overline{\bar{X}}$ and $\bar{S}$, the center line and upper and lower control limits for $\bar{X}$ control chart are:

$$
U C L=\overline{\bar{X}}+A_{3} \bar{S} \quad C L=\overline{\bar{X}} \quad L C L=\overline{\bar{X}}-A_{3} \bar{S}
$$

The center line and upper and lower control limits for S control chart are:

$$
U C L=B_{4} \bar{S} \quad C L=\bar{S} \quad L C L=B_{3} \bar{S}
$$

where the constant $A_{3}, B_{3}$ and $B_{4}$ are tabulated for various sample sizes.

The LCL for S chart calculated by equation (9) may be negative when the sample size is small. In this case, it is customary to set LCL to zero. X-bar and S control charts are preferred when the sample size is greater than 10 . 
In many situations, the sample size used for process control is $\mathrm{n}=1$; that is, the sample consists of an individual unit (Montgomery \& Runger, 2003). In such situations, the individuals control chart is useful. The control chart for individuals uses the moving range of two successive observations to estimate the process variability. The moving range is defined as $M R_{i}=\left|X_{i}-X_{i-1}\right|$ and an estimate of $\sigma$ is

$$
\hat{\sigma}=\frac{\overline{M R}}{d_{2}}=\frac{\overline{M R}}{1.128}
$$

because $d_{2}$ is equal to 1.128 when two consecutive observations are used to calculate a moving range. It is also possible to establish a control chart on the moving range using $D_{3}$ and $D_{4}$ for $n=2$.

The center line and upper and lower control limits for a control chart for individuals are

$$
U C L=\bar{X}+3 \frac{\overline{M R}}{d_{2}}=\bar{X}+3 \frac{\overline{M R}}{1.128} \quad C L=\bar{X} \quad L C L=\bar{X}-3 \frac{\overline{M R}}{d_{2}}=\bar{X}-3 \frac{\overline{M R}}{1.128}
$$

and for a control chart for moving ranges

$$
U C L=D_{4} \overline{M R}=3.267 \overline{M R} \quad C L=\overline{M R} \quad U C L=D_{3} \overline{M R}=0
$$

\section{Multivariate control charts}

Multivariate analyses utilize the additional information due to the relationships among the variables and these concepts may be used to develop more efficient control charts than the simultaneous operation of several univariate control charts. The most popular multivariate SPC charts are the Hotelling's $\mathrm{T}^{2}$ and multivariate exponentially weighted moving average (MEWMA) (Elsayed, 2000). Multivariate control chart for process mean is based heavily upon Hotelling's $\mathrm{T}^{2}$ distribution, which was introduced by Hotelling (1947). Other approaches, such as a control ellipse for two related variables and the method of principal components, are introduced by Jackson (1956) and Jackson (1959).

Hotelling's $\mathrm{T}^{2}$ distribution is the multivariate analogue of the univariate $t$ distribution for the use of known standard value $\mu$ or individual observations 
[(Sultan, 1986), (Blank, 1988), and (Morrison, 1990)]. One of the first researchers in the area of multivariate SPC was Hotelling (1947) whose research explored multivariate quality control.

Under the null hypothesis of the process being in control and the assumption of independent identical multivariate normality, the chart statistic follows Hotelling's $T^{2}$

$$
T^{2}=n\left(\bar{x}_{i}-\bar{x}\right)^{\prime} S^{-1}\left(\bar{x}_{i}-\bar{x}\right) \approx \frac{p(m-1)(n-1)}{m n-m-p+1} F_{p, m n-m-p+1}
$$

Alt (1985) pointed out that it is important to carefully select the control limit to guarantee the process is in control in Phase I. After parameter estimation, a preliminary charting for Phase I samples should be run to see whether the chart is well constructed, before stepping into Phase II to monitor the future samples. The control limits are set according to the specified level of significance:

$$
U C L=\frac{p(m-1)(n-1)}{m n-m-p+1} F_{\alpha, p, m n-m-p+1}
$$

And since usually the shift in mean vector and the increase of covariance are of interest, $\mathrm{LCL}=0$. The chart signals when $\mathrm{T}^{2}>\mathrm{UCL}$. After confirming the process is in control, then in Phase $I 1$, the Hotelling $\mathrm{T}^{2}$ becomes, with future sample mean $\left(\bar{x}_{j}\right)$, of size $\mathrm{n}$ :

$$
T^{2}=n\left(\bar{x}_{j}-\bar{x}\right)^{\prime} S^{-1}\left(\bar{x}_{j}-\bar{x}\right) \approx \frac{p(m-1)(n-1)}{m n-m-p+1} F_{p, m n-m-p+1}
$$

Similar to that in Shewhart chart, although the Phase II samples and their mean, $\bar{x}_{j}$, are independent, the $\mathrm{T}^{2}$ for different Phase II samples are not independent of each others because they share the same Phase I grand mean $\overline{\bar{x}}$ and pooled covariance matrix $\bar{S}$.

In Phase II, however, the statistic still has an F distribution:

$$
T^{2}=\left(\bar{x}_{j}-\bar{x}\right) S^{-1}\left(\bar{x}_{j}-\bar{x}\right) \approx \frac{p(m+1)(m-1)}{m^{2}-m p} F_{p, m-p}
$$


But usually $\chi^{2}(p)$ can be used to approximate the distribution when $\mathrm{m}$ is large. This chi-square approximation makes more conservative control limits than the original $\mathrm{F}$ distribution.

A straightforward multivariate extension of the univariate EWMA control chart was first introduced by Lowry, Woodall, Champ, and Rigdon (1992). They developed a multivariate EWMA (MEWMA) control chart. It is an extension to the univariate EWMA,

$$
Z_{i}=\Lambda \overline{X_{i}}+(I-\Lambda) Z_{i-1}
$$

Where $\mathrm{I}$ is the identity matrix, $Z_{i}$ is the $\mathrm{i}^{\text {th }}$ EWMA vector, $\bar{X}_{i}$ is the average $\mathrm{i}^{\text {th }}$ observation vector $\mathrm{i}=1,2, \ldots, \mathrm{n}, \Lambda$ is the weighting matrix.

The plotting statistic is

$$
T_{i}^{2}=Z_{i}^{\prime} \Sigma_{Z_{i}}^{-1} Z_{i}
$$

Lowry, Woodall, Champ \& Rigdon (1992) showed that the $(k, I)$ element of the covariance matrix of the $i^{\text {th }}$ EWMA, $\Sigma_{Z i}$, is

$$
\Sigma_{Z i}(k, l)=\lambda_{k} \lambda_{l} \frac{\left[1-\left(1-\lambda_{k}\right)^{i}\left(1-\lambda_{l}\right)^{i}\right]}{\left[\lambda_{k}+\lambda_{l}-\lambda_{k} \lambda_{l}\right]} \sigma_{k, l}
$$

where $\sigma_{k, l}$ is the $(\mathrm{k}, \mathrm{l})$ th element of $\Sigma$, the covariance matrix of the $\bar{X}$ 's.

If $\lambda_{1}=\lambda_{2}=\ldots \ldots=\lambda_{P}=\lambda$, then the above expression is simplified to:

$$
\Sigma_{z i}=\frac{\lambda}{2-\lambda}\left[1-(1-\lambda)^{2 i}\right] \Sigma
$$

where $\Sigma$ is the covariance matrix of the input data.

There is a further simplification. When i becomes large, the covariance matrix may be expressed as:

$$
\Sigma_{Z i}=\frac{\lambda}{2-\lambda} \Sigma
$$


Process variability is defined by the covariance matrix, $\Sigma_{p \times p}$ where the main diagonal elements are the variances of the individual process variables, and the off-diagonal elements are the covariances. There are two procedures to control the process variability: the first procedure is a direct extension of the univariate $\mathrm{S}^{2}$ control chart and the second one is based on the sample generalized variance $|S|$. This statistic, which is the determinant of the sample covariance matrix, is a widely used measure of multivariate dispersion. Montgomery and Wadsworth (1972) suggested a multivariate control chart for process dispersion based on the sample generalized variance, $|S|$. The approach uses an asymptotic normal approximation to develop a control chart for $|S|$. For this method the parameters of the control chart are (Montgomery, 2005):

$$
\begin{gathered}
U C L=\left(|S| / b_{1}\right)\left(b_{1}+3 b_{2}{ }^{1 / 2}\right) \\
C L=|S| \\
U C L=\left(|S| / b_{1}\right)\left(b_{1}-3 b_{2}{ }^{1 / 2}\right)
\end{gathered}
$$

where:

$$
b_{1}=\left[1 /(n-1)^{p}\right] \prod_{i=1}^{p}(n-i)
$$

and

$$
b_{2}=\left[1 /(n-1)^{2 p}\right] \prod_{i=1}^{p}(n-i)\left[\prod_{j=1}^{p}(n-j+2)-\prod_{j=1}^{p}(n-j)\right]
$$

\section{SPC of autocorrelated observations}

Conventional control charts are based on the assumption that the observations are independently and identically distributed (IID) over time. With increasing automation, however, inspection rates have increased. Consequently, data are more likely to be autocorrelated, which can significantly deteriorate control charting performance. It was shown that autocorrelation deteriorates the ability of 
the Shewhart chart to correctly separate the assignable causes from the common causes (Alwan, 1992).

There are circumstances where the underlying independence assumptions for the Shewhart control charts are violated, i.e., the observations are autocorrelated. This is a common consequence of processes that are driven by inertia forces in process industries and frequent sampling in the parts industries (Montgomery, 2005). Several authors including Alwan and Roberts (1988), Alwan (1992), and Harris and Ross (1991) have shown that in the presence of autocorrelation, the traditional control charts will increase the false alarm rates. When applying control charts to a process, it is pertinent to understand the process characteristics and acknowledge the violations of the assumptions. Given measurements, $Y_{1}, Y_{2}, \ldots, Y_{N}$ at time $X_{1}$, $X_{2}, \ldots, X_{N}$, the lag $k$ autocorrelation function is defined as

$$
r_{k}=\frac{\sum_{i=1}^{N-k}\left(Y_{i}-\bar{Y}\right)\left(Y_{i+k}-\bar{Y}\right)}{\sum_{i=1}^{N}\left(Y_{i}-\bar{Y}\right)^{2}}
$$

Two approaches have been advocated for dealing with the autocorrelation. The first approach uses standard control charts on original observations, but adjusts the control limits and the methods of estimating parameters to account for the autocorrelation in the observations (VanBrackle \& Reynolds, 1997; Lu \& Reynolds, 1999). This approach is particularly applicable when the level of autocorrelation is not high. A second approach for dealing with autocorrelation fits time series model such as ARIMA models to the process observations. The procedure forecasts observations from previous values and then computes the forecast errors or residuals.

\section{Special control charts}

When the values of a variable are intended to have a special fit or trend, the standard control charts may not be suitable for monitoring this variable. In this case, a regression should be used to determine the best fit of the data. Then, a special control charts can be applied for monitoring the variable taking into consideration the best fit of the data. The most common special control charts are Trend control charts and ARIMA control charts which depend respectively on the linear models and ARIMA models. 
Regression can be used for prediction (including forecasting of time-series data), inference, hypothesis testing, and modeling of causal relationships. These applications of regression rely heavily on how the underlying assumptions are satisfied. Regression analysis has been criticized as being misused for these purposes in many cases where the appropriate assumptions can't be verified to hold. One factor contributing to the misuse of regression is that it can take considerably more skill to critique a model than to fit a model (Cook \& Weisberg, 1982).

Box and Jenkins (1970) consolidated many commonly used time series techniques into a structured model-building process that emphasizes simple, parsimonious models. The time series models used in Box-Jenkins forecasting are called autoregressive-integrated-moving average models, or ARIMA models for short. To encompass the diverse forecasting applications that arise in practice, this class of models has to be, and is, very large. For example, that exponential smoothing, autoregressive models, and random-walk models are all special forms of ARIMA models.

Box-J enkins modeling relies heavily on the use of three familiar time series tools: differencing, autocorrelation function (acf), and partial autocorrelation function (pacf). Differencing is used to reduce non-stationary series ones. The acf and pacf are then used to identify an appropriate ARIMA model and the required number of parameters. After the model is identified, parameter estimates are obtained; that is, the selected model is fit to the available data. The algorithm is based on the least square concept and usually requires several iterations before producing the desired estimates. It is necessary, therefore, to rely on computer programs to implement the Box-Jenkins procedure. ARIMA is a mix of autoregressive, integrated, and moving average terms in the same model (Farnum \& Stanton 1989). Autoregressive-integrated-moving average model of order $p, d$, and $q$, $\operatorname{ARIMA}(p, d, q)$ is:

$$
\left(1-\sum_{i=1}^{p} \Phi_{i} L^{i}\right)(1-L)^{d} X_{t}=\left(1+\sum_{i=1}^{q} \theta_{i} L^{i}\right) \varepsilon_{t}
$$


where

$$
\begin{array}{ll}
\mathrm{L} & =\mathrm{X}_{\mathrm{t}-1} / \mathrm{X}_{\mathrm{t}} \quad \text { (lag operator). } \\
\mathrm{X}_{\mathrm{t}} & =\text { the actual value of the series at time } \mathrm{t} . \\
\mathrm{X}_{\mathrm{t}-1} & =\text { the value of the series at time } \mathrm{t}-1 . \\
\varepsilon_{t} & =\text { the error terms. } \\
\Phi_{i} & =\text { the autoregressive parameter. } \\
\theta_{i} & =\text { the moving average parameter. } \\
\mathrm{i} & =\text { an integer counter from } 1 \text { to } \mathrm{p} \text { and } \mathrm{q} .
\end{array}
$$

When plotting a certain data, if a definite upward trend over time is detected, it is reasonable to conjecture that the model should contain a trend component. The simplest model with a trend component is a linear trend model:

$$
Y_{t}=a+b t+\varepsilon_{t}
$$

$Y_{t}$ is the dependent variable, $t$ is the independent variable, $a, b$ are the parameters, $\varepsilon_{t}$ is an error term, and the subscript $t$ indexes a particular data point. If we believe that the data can be described by a linear trend model, the next step is to determine which values of $a$ and $b$ best describe the process.

We can then use the model

$$
F_{t}=a+b t
$$

to forecast the future value of $Y_{t}$ because the errors are assumed to average zero.

From elementary statistics we know that if a random variable $Y$ is a linear function of some variable $X$-that is, $Y=a+b X$, then for a give set of $n$ paired observations of the variables $\left(x_{1}, y_{1}\right), \ldots \ldots \ldots . . .,\left(x_{n}, y_{n}\right)$, the least squares estimators for $\mathrm{a}$ and $\mathrm{b}$ are

$$
b=\frac{n\left(\sum x_{i} y_{i}\right)-\left(\sum x_{i}\right)\left(\sum y_{i}\right)}{n\left(\sum x_{i}^{2}\right)-\left(\sum x_{i}\right)^{2}}
$$




$$
a=\frac{\sum y_{i}-b \sum x_{i}}{n}
$$

So, for the linear trend process in equation (27) we can treat time t as the variable $X$ and $Y_{t}$ as the variable $Y$ (Martinich, 1997).

\section{Practical Application and Discussion}

Cold rolling is a metal working process in which metal is deformed by passing it through rollers at a temperature below its recrystallization temperature (Figure 1 and 2). Cold rolling increases the yield strength and hardness of a metal by introducing defects into the metal's crystal structure. These defects prevent further slip and can reduce the grain size of the metal, resulting in Hall-Petch hardening. The aim of the rolling process is to reduce the thickness of a strip to a desired value with a good dimensional accuracy, surface finish, and good mechanical properties. This is done by applying a force to the strip while moving through the roll gap. The most effective parameters in cold rolling processes are: rolling force, strip speed, and the resulting strip thickness (Reed-Hill, 1994).
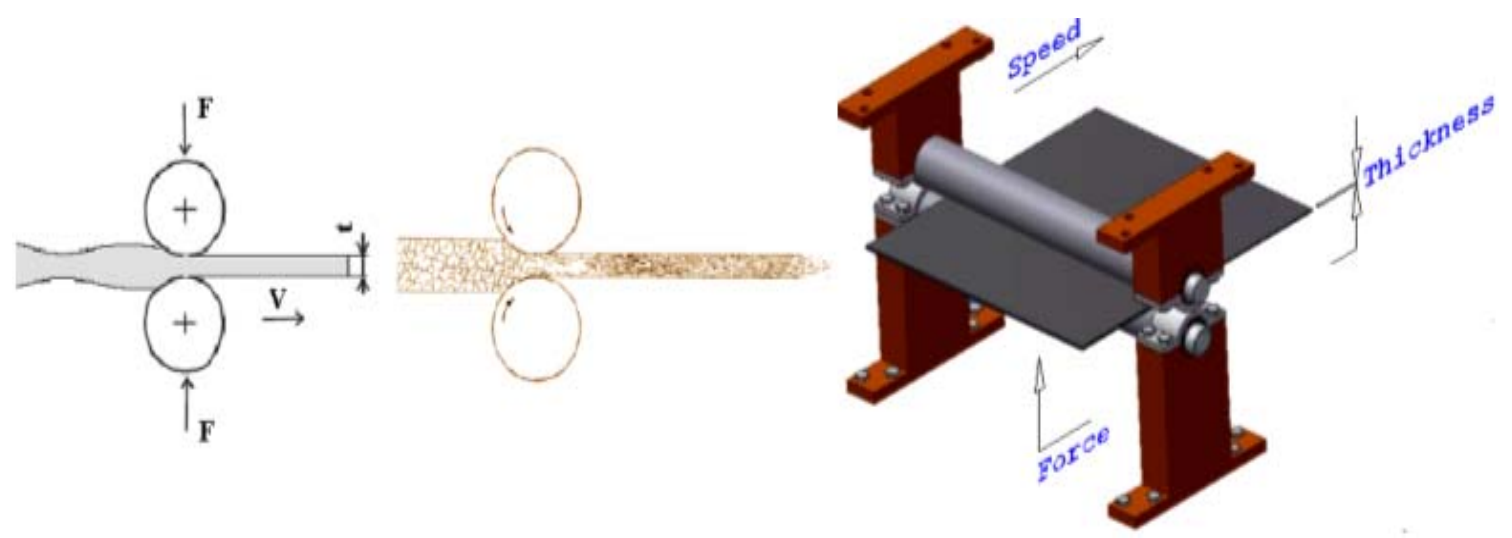

Figures $1 \& 2$. "Cold rolling process" \& "Solid model for cold rolling process".

The application study of this paper was carried out in Galvametal Company which is located in Egypt. The hot rolled coil (as a raw material) is passed through a sequence of processes in order to obtain the cold rolled coils or the galvanized cold rolled coils. This sequence of processes is shown in Figure 3. 


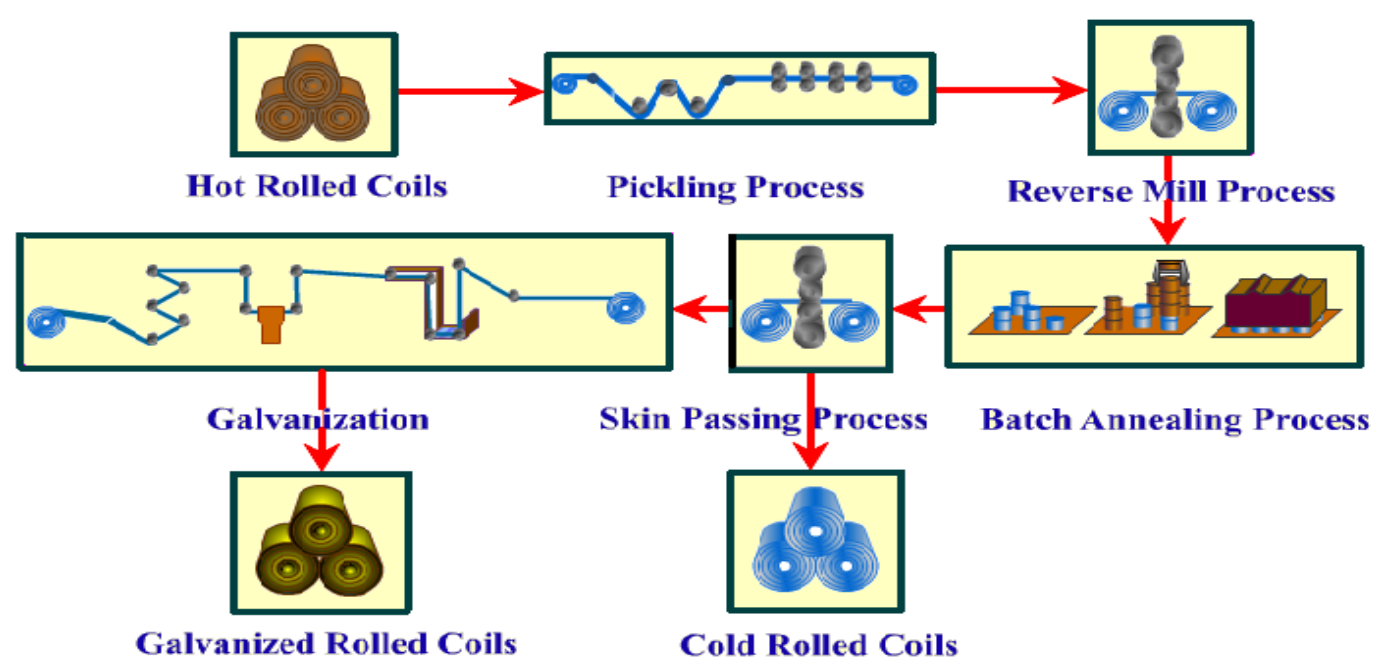

Figure 3. "A flow chart of the rolling and the galvanization for coils".

\subsection{Run charts}

Due to the nature of the cold rolling process, there are always disturbances and dynamic behavior, especially in the start and at the end of the rolling pass (that is why the well-known companies discard the start and the end of the cold rolled sheet).

Run charts are constructed for the three variables in order to help in determining the zone of the pass (effective zone) in which the sheet is subjected to the actual deformation.

From run charts, the common zone for the three variables was determined, and it will be the effective zone, which we will analyze. Random samples are taken from this zone at equal time intervals ( 25 samples of 5 observations each).

\begin{tabular}{|l|c|c|c|}
\hline $\begin{array}{c}\text { Variables } \\
\text { Characteristics }\end{array}$ & Force $(\mathbf{K N})$ & Speed $\mathbf{( m / \mathbf { m i n } )}$ & Thickness $(\mathbf{m m})$ \\
\hline Data of range & $\begin{array}{c}368 \text { observations } \\
\text { ranging from }\end{array}$ & $\begin{array}{c}368 \text { observations } \\
\text { ranging from } \\
703.0 \text { to } 963.0\end{array}$ & $\begin{array}{c}368 \text { observations } \\
\text { ranging from } \\
0.874 \text { to } 1.068\end{array}$ \\
\hline Median & 888.5 & 457.5 & 0.97 \\
\hline
\end{tabular}

Table 1. "Range and median of force, speed, and thickness data". 

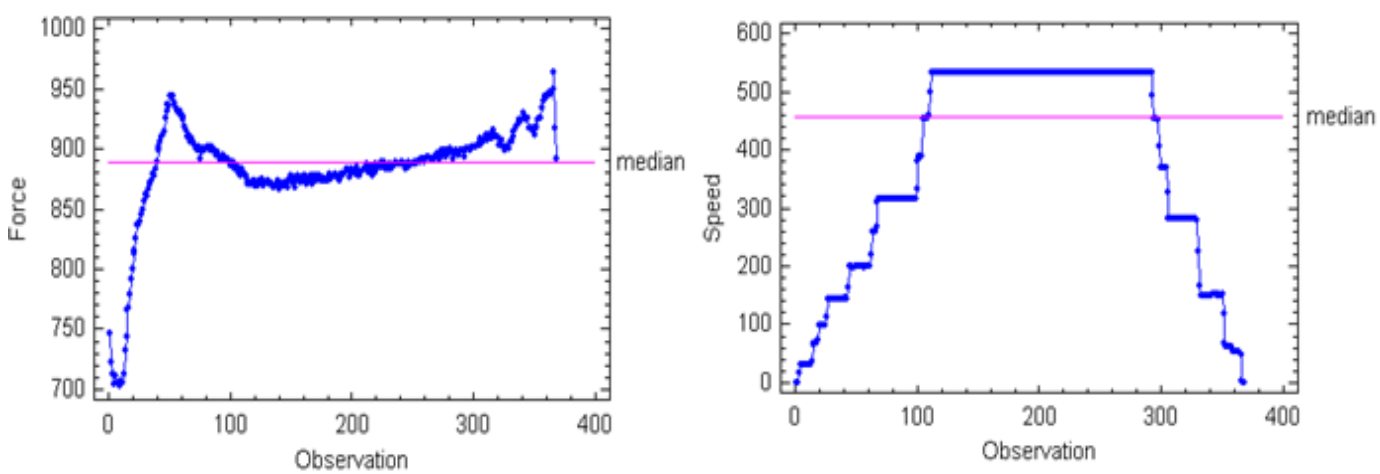

Figures $4 \& 5$. "Run chart for force" \& "Run chart for speed".

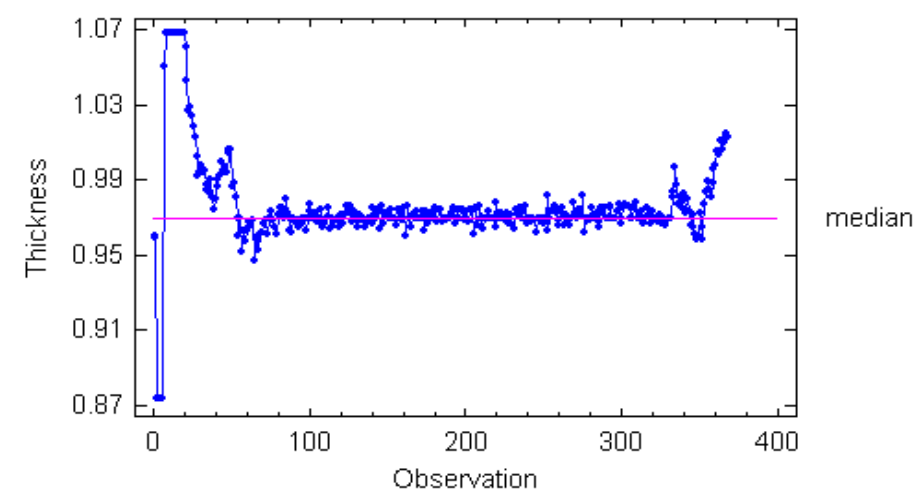

Figure 6. "Run chart for thickness".

\subsection{The descriptive method}

\begin{tabular}{|l|l|l|l|}
\hline \multirow{2}{*}{ Lag Variables } & \multicolumn{3}{|l|}{ Estimated Autocorrelation Coefficient } \\
\cline { 2 - 4 } & Force & Speed & Thickness \\
\hline $\mathbf{1}$ & 0.823852 & 0.187407 & -0.134394 \\
\hline $\mathbf{2}$ & 0.797439 & -0.0190827 & -0.105766 \\
\hline $\mathbf{3}$ & 0.78677 & 0.263019 & 0.397511 \\
\hline $\mathbf{4}$ & 0.755361 & 0.0208762 & -0.261638 \\
\hline $\mathbf{5}$ & 0.757208 & -0.210713 & -0.0582364 \\
\hline $\mathbf{6}$ & 0.69999 & -0.035571 & 0.143712 \\
\hline $\mathbf{7}$ & 0.716157 & 0.246531 & -0.304124 \\
\hline $\mathbf{8}$ & 0.694055 & 0.00438791 & 0.0749056 \\
\hline $\mathbf{9}$ & 0.667377 & 0.0831238 & 0.0606449 \\
\hline $\mathbf{1 0}$ & 0.673898 & 0.472185 & -0.360614 \\
\hline
\end{tabular}

Table 2. "Estimated autocorrelation coefficients of force, speed and thickness". 

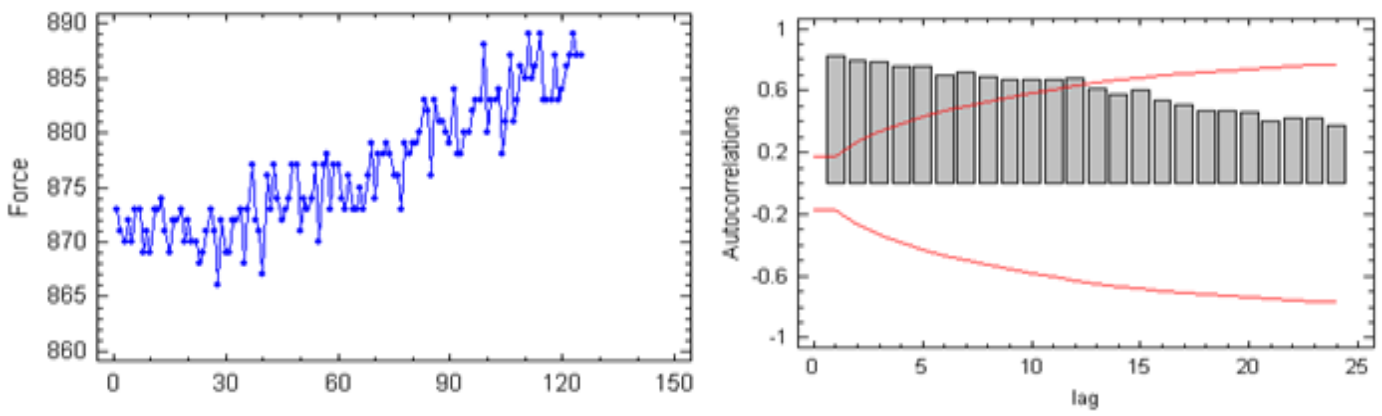

Figures $7 \& 8$. "Time series plot for force" \& "Estimated autocorrelation for force".
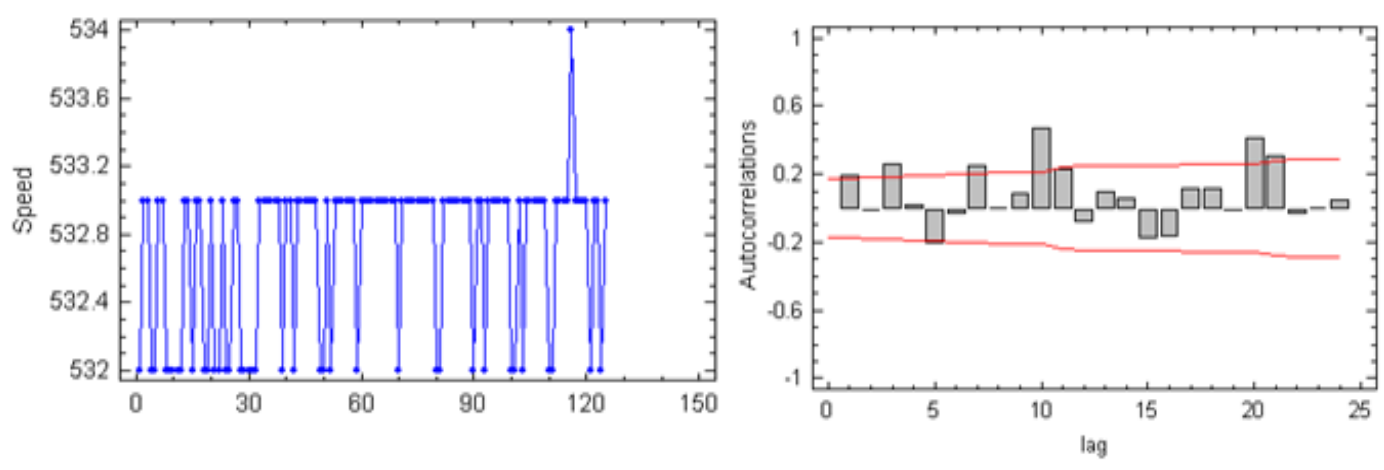

Figures $9 \& 10$. "Time series plot for speed" \& "Estimated autocorrelation for speed".
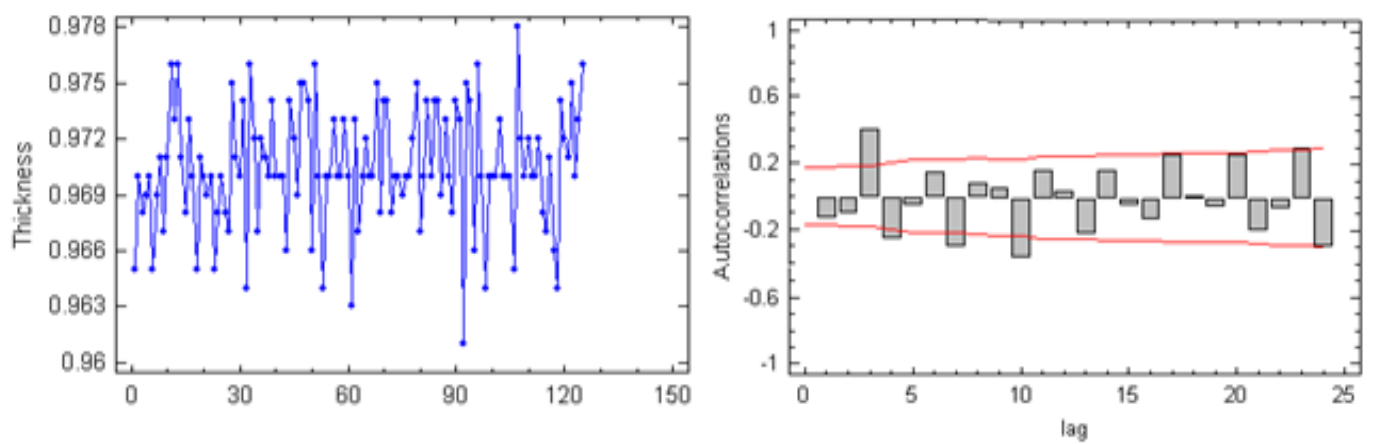

Figures $11 \& 12$. "Time series plot for thickness" \& "Estimated autocorrelation for thickness".

These figures show the estimated autocorrelations between values of each variable at various lags. The lag $k$ autocorrelation coefficient measures the correlation between values of each variable at time $t$ and time $t-k$. Also shown probability limits around 0 . If the autocorrelation estimate at a certain lag is outside the red $95 \%$ probability limits on the autocorrelation graphs, then there is a significant autocorrelation at that lag. 


\subsection{Exponential weighted moving average (EWMA) charts}

\begin{tabular}{|c|c|c|c|c|}
\hline \multicolumn{2}{|c|}{$\begin{array}{ll}\text { Charts } & \text { Variables }\end{array}$} & Force & Speed & Thickness \\
\hline \multirow{5}{*}{$\begin{array}{l}\frac{t}{0} \\
\frac{c}{U} \\
v\end{array}$} & Period & $\# 1-25$ & $\# 1-25$ & $\# 1-25$ \\
\hline & UCL:+3.0 sigma & 4.37304 & 0.935127 & 0.00650956 \\
\hline & Centerline & 2.09325 & 0.44762 & 0.00311595 \\
\hline & LCL:-3.0 sigma & 0.0 & 0.0 & 0.0 \\
\hline & Out-of-control signals & 0 & 0 & 0 \\
\hline \multirow{5}{*}{ 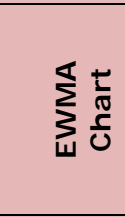 } & Period & $\# 1-25$ & $\# 1-25$ & $\# 1-25$ \\
\hline & UCL: +3.0 sigma & 877.764 & 532.917 & 0.971954 \\
\hline & Centerline & 876.768 & 532.704 & 0.970472 \\
\hline & LCL:-3.0 sigma & 875.772 & 532.491 & 0.96899 \\
\hline & Out-of-control signals & $\begin{array}{l}6 \text { above UCL } \\
16 \text { below } L C L\end{array}$ & $\begin{array}{l}0 \text { above UCL } \\
2 \text { below } L C L\end{array}$ & 0 \\
\hline \multirow{4}{*}{ 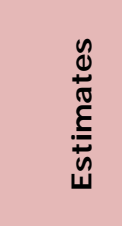 } & Period & $\# 1-25$ & $\# 1-25$ & \#1-25 \\
\hline & Process mean & 876.768 & 532.704 & 0.970472 \\
\hline & * Process sigma & 2.22693 & 0.476204 & 0.00331493 \\
\hline & Average S & 2.09325 & 0.44762 & 0.00311595 \\
\hline
\end{tabular}

* Sigma estimated from average $\mathrm{S}$ with bias correction.

Table 3. "EWMA and S charts parameters of force, speed, and thickness".

EWMA chart is designed to determine whether the process is in a state of statistical control or not. It is used for detecting small shifts. The control charts are constructed under the assumption that the subgroups are rationally formed and that the data is independent.
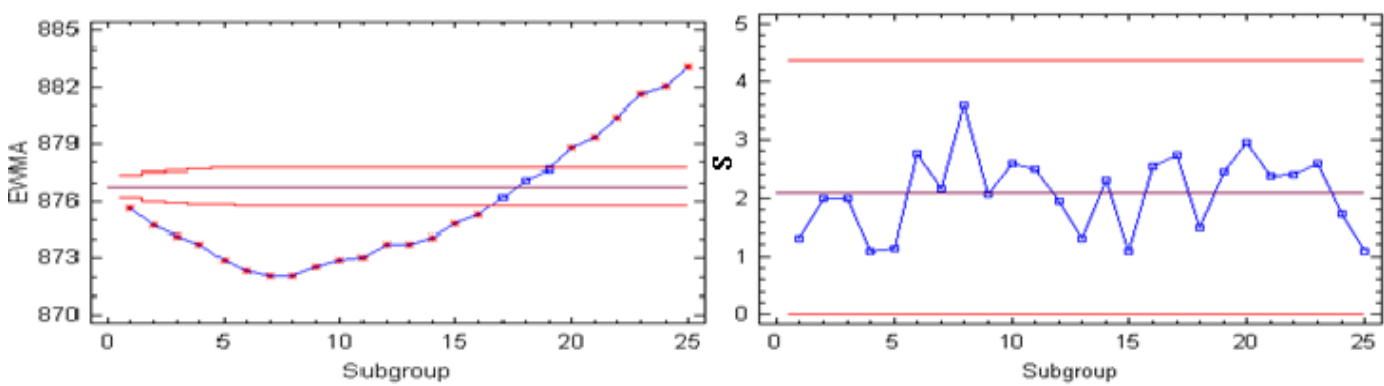

Figures $13 \& 14$. "EWMA chart for force" \& "S chart for force".
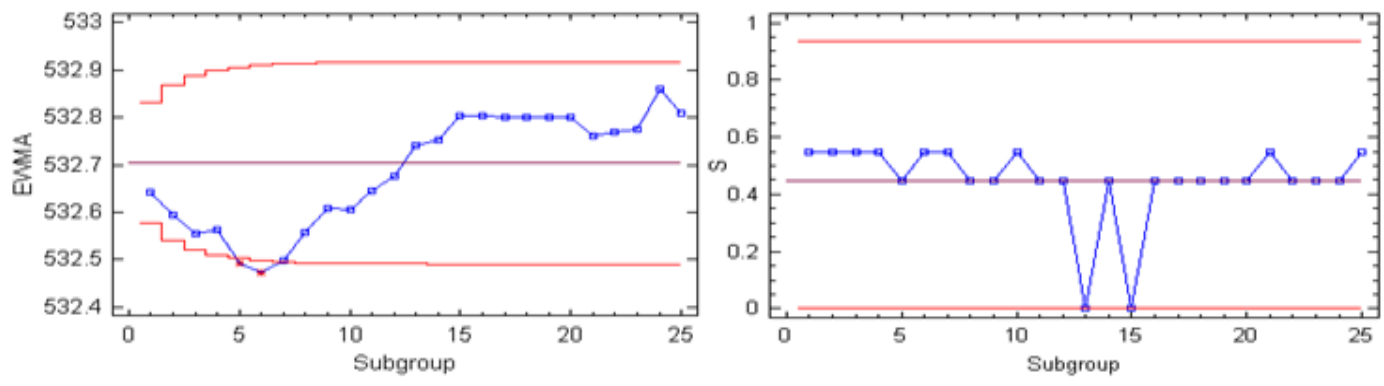

Figures $15 \& 16$. "EWMA chart for speed" \& "S chart for speed". 

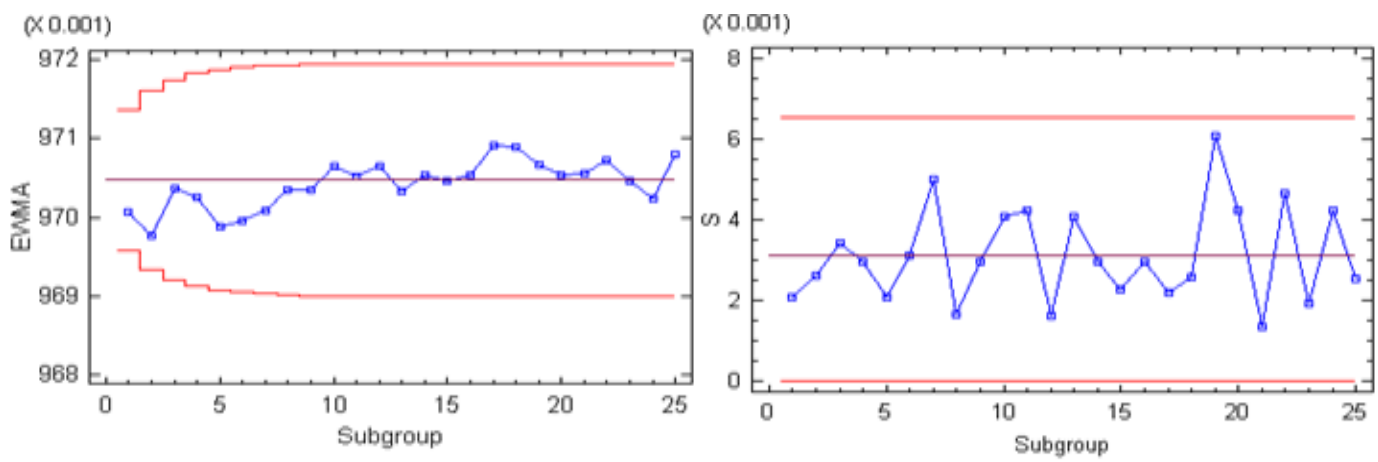

Figures $17 \& 18$. "EWMA chart for thickness" \& "S chart for thickness".

\subsection{Fitting models}

\begin{tabular}{|c|c|c|c|c|c|}
\hline \multirow{2}{*}{\multicolumn{2}{|c|}{ Characteristics }} & \multicolumn{2}{|l|}{ Force } & \multirow{2}{*}{$\begin{array}{l}\text { Speed } \\
\text { ARI MA } \\
(3,0,2) \\
\end{array}$} & \multirow{2}{*}{$\begin{array}{l}\text { Thickness } \\
\text { ARI MA } \\
(3,0,2) \\
\end{array}$} \\
\hline & & \multirow{2}{*}{$\begin{array}{l}\text { ARI MA } \\
(3,0,2) \\
2.46543 \\
\end{array}$} & \multirow{2}{*}{$\begin{array}{l}\text { Linear trend }= \\
867.919+0.140455 t \\
2.60214\end{array}$} & & \\
\hline \multirow{5}{*}{$\underset{n}{\stackrel{u}{n}}$} & RMSE & & & 0.414408 & 0.00280303 \\
\hline & MAE & 1.98608 & 2.08854 & 0.332239 & 0.0021463 \\
\hline & MAPE & 0.226464 & 0.238293 & 0.0623856 & 0.221233 \\
\hline & ME & 0.169516 & $-7.18501 E-14$ & -0.0001681 & 0.00000287 \\
\hline & MPE & 0.0187374 & -0.000870975 & -0.0000887 & -0.0004923 \\
\hline \multirow{5}{*}{$\begin{array}{l}\frac{1}{d} \\
\stackrel{0}{0} \\
\frac{E}{0} \\
\frac{0}{0} \\
\alpha\end{array}$} & $\operatorname{AR}(1)$ & 0.099304 & & -0.0292211 & -1.05671 \\
\hline & $A R(2)$ & 0.854016 & & -0.710946 & -0.849484 \\
\hline & $A R(3)$ & 0.0789981 & & 0.453948 & 0.133565 \\
\hline & MA(1) & -0.050374 & & -0.296037 & -1.1424 \\
\hline & MA(2) & 0.817067 & & -0.82529 & -0.926345 \\
\hline
\end{tabular}

Table 4. "Fitting models of force, speed, and thickness".

For ARIMA $(3,0,2)$ model ( where $\left.L=X_{t-1} / X_{t}\right)$ :

$$
\left[1-A R(1) L^{1}-A R(2) L^{2}-A R(3) L^{3}\right] X_{t} \approx 1+M A(1) L^{1}+M A(2) L^{2}
$$

These models present the best regression for values of variables. The data cover 125 time periods. An autoregressive integrated moving average (ARIMA) model has been selected for the three variables. This model assumes that the best regression for data is given by a parametric model relating the most recent data values to previous data values and previous noise. Also for the force data, a linear trend model has been selected. This model assumes that the best regression for future data is given by a linear regression line fit to all previous data. 
Table 7 summarizes the performance of the currently selected model in fitting the historical data. It displays:

(1)The root mean squared error (RMSE)

(2) The mean absolute error (MAE)

(3) The mean absolute percentage error (MAPE)

(4) The mean error (ME)

(5) The mean percentage error (MPE)

The first three statistics measure the magnitude of the errors. A better model will give a smaller value. The last two statistics measure bias. A better model will give a value close to zero.
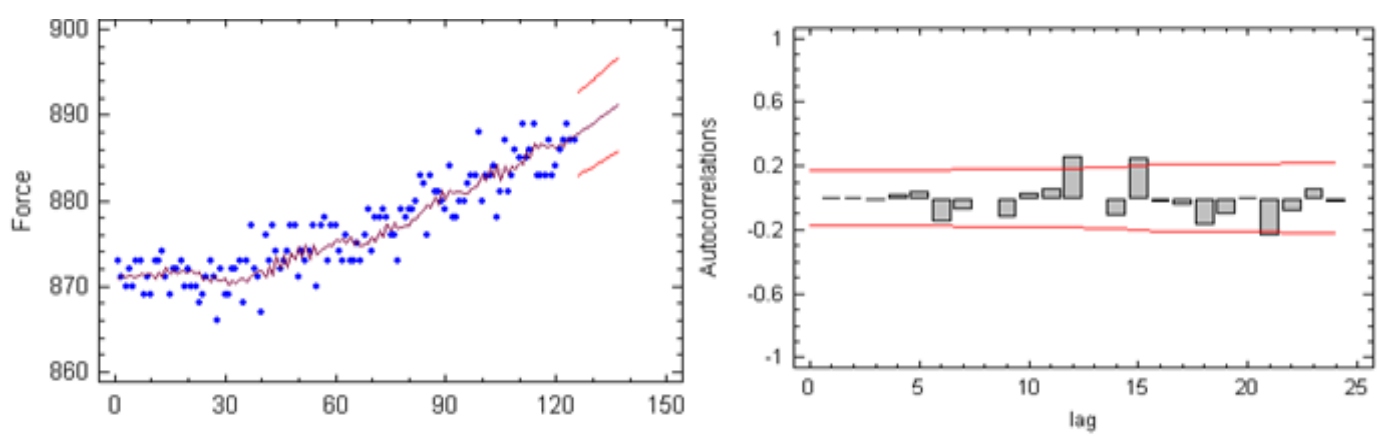

Figures $19 \& 20$. "Time sequence plot for force ARIMA $(3,0,2)$ with constant" \& “Estimated autocorrelation for force ARIMA $(3,0,2)$ with constant".
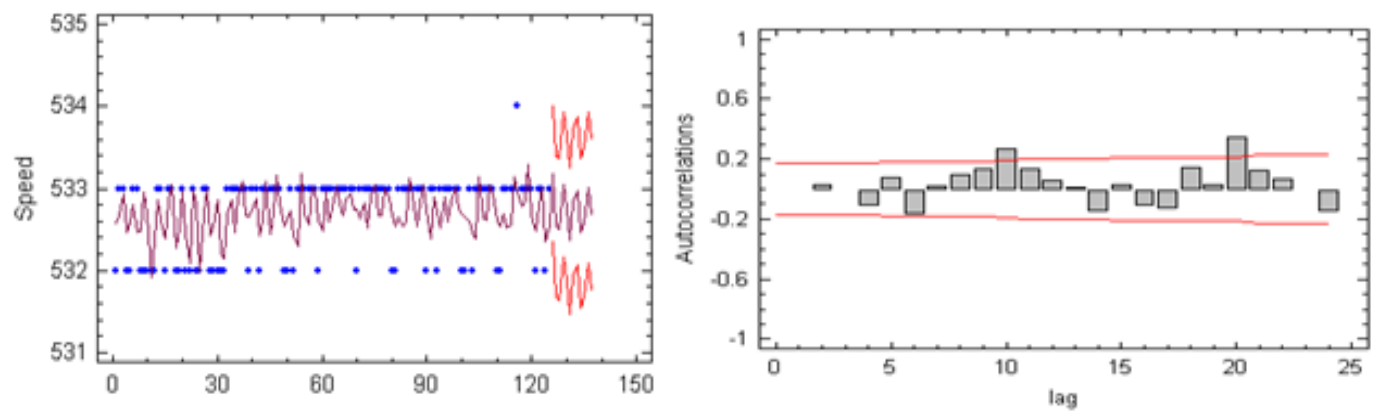

Figures $21 \& 22$. "Time sequence plot for speed ARIMA $(3,0,2)$ with constant" \& “Estimated autocorrelation for speed ARIMA $(3,0,2)$ with constant". 

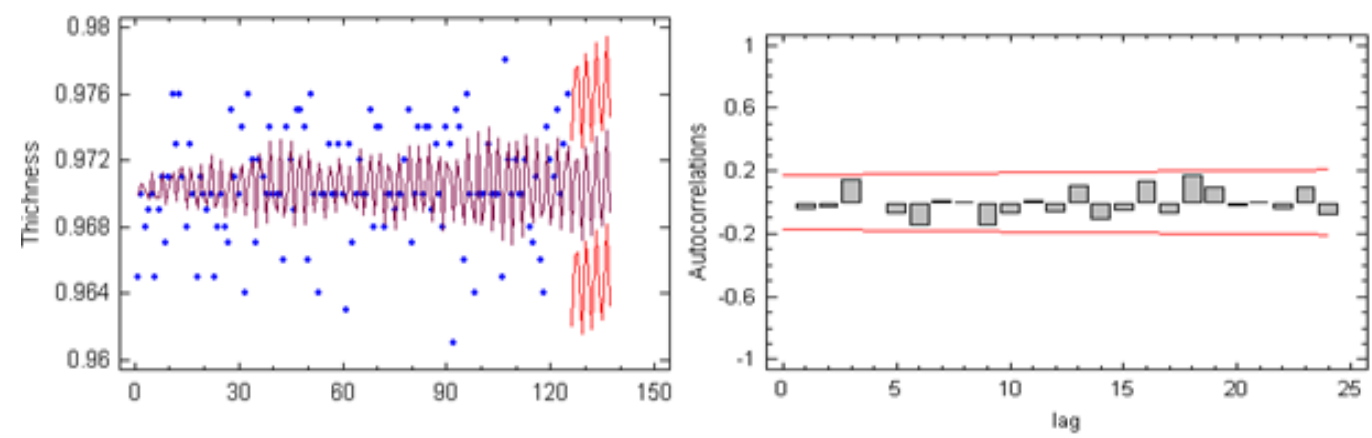

Figures $23 \& 24$. "Time sequence plot for thickness ARIMA $(3,0,2)$ with constant" \&

“Estimated autocorrelation for thickness ARIMA $(3,0,2)$ with constant".
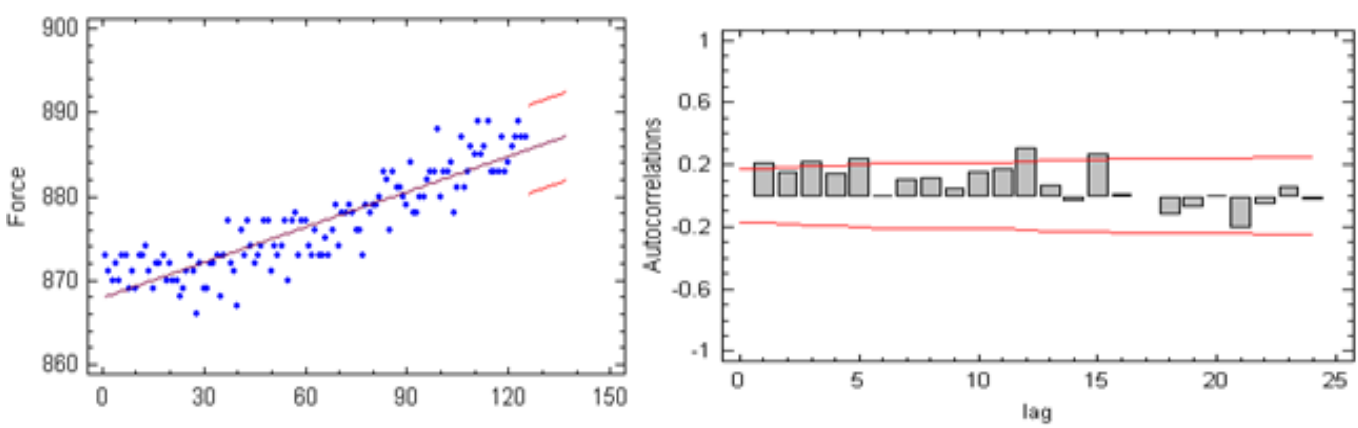

Figures $25 \& 26$. "Time sequence plot for force Linear trend $=867.919+0.140455 \mathrm{t}$ " \& "Estimated autocorrelation for force Linear trend $=867.919+0.140455 \mathrm{t}$ ".

\section{ARIMA charts}

The ARIMA chart is designed to determine whether the process is in a state of statistical control or not. The control charts are constructed under the assumption that the data come from a time series set of observations.
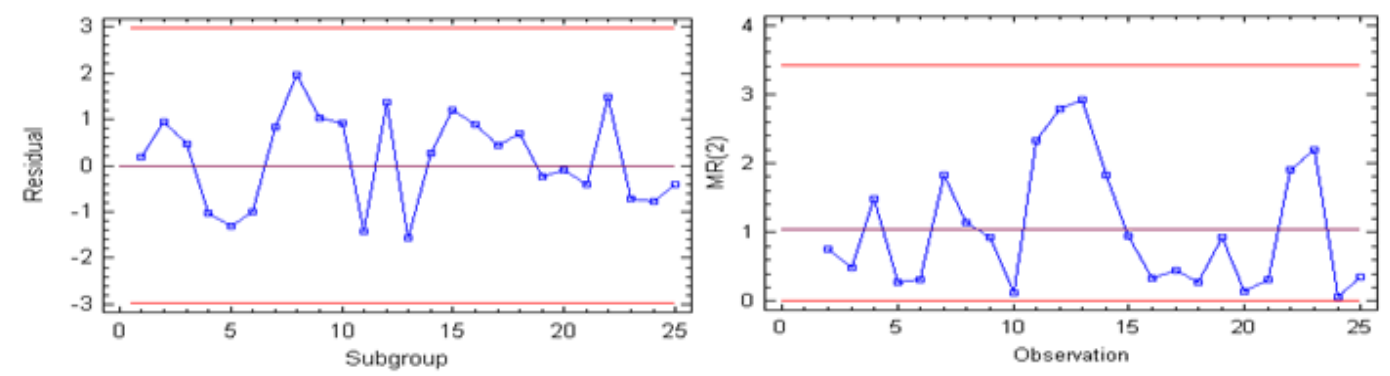

Figures $27 \& 28$. "ARIMA chart for force" \& "MR(2) chart for force residual". 


\begin{tabular}{|c|c|c|c|c|}
\hline \multicolumn{2}{|c|}{ Charts Variables } & Force & Speed & Thickness \\
\hline \multirow{5}{*}{$\begin{array}{l}\frac{t}{0} \\
\frac{\mathrm{U}}{\mathrm{U}} \\
\frac{\mathrm{N}}{\mathrm{N}} \\
\frac{\tilde{c}}{\Sigma}\end{array}$} & Period & \#1-25 & \#1-25 & \#1-25 \\
\hline & UCL:+3.0 sigma & 3.41748 & 0.48673 & 0.00411079 \\
\hline & Centerline & 1.04597 & 0.148971 & 0.00125817 \\
\hline & LCL:-3.0 sigma & 0.0 & 0.0 & 0.0 \\
\hline & Out-of-control signals & 0 & 0 & 0 \\
\hline \multirow{5}{*}{$\begin{array}{l}\frac{t}{0} \\
\frac{\delta}{U} \\
\frac{\alpha}{\Sigma} \\
\frac{\Sigma}{\alpha}\end{array}$} & Period & \#1-25 & $\# 1-25$ & \#1-25 \\
\hline & UCL: + 3.0 sigma & 2.98774 & 0.638895 & 0.00444744 \\
\hline & Centerline & 0.0 & 0.0 & 0.0 \\
\hline & LCL:-3.0 sigma & -2.98774 & -0.638895 & -0.00444744 \\
\hline & Out-of-control signals & 0 & 0 & 0 \\
\hline \multirow{4}{*}{ 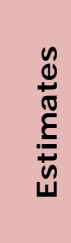 } & Period & $\# 1-25$ & \#1-25 & $\# 1-25$ \\
\hline & Process mean & 868.112 & 532.694 & 0.9705 \\
\hline & * Process sigma & 0.927276 & 0.132066 & 0.0011154 \\
\hline & Mean MR(2) & 1.04597 & 0.148971 & 0.00125817 \\
\hline
\end{tabular}

* Sigma estimated from average $\mathrm{S}$ with bias correction.

Table 5. "ARIMA and MR(2) charts parameters of force, speed and, thickness".
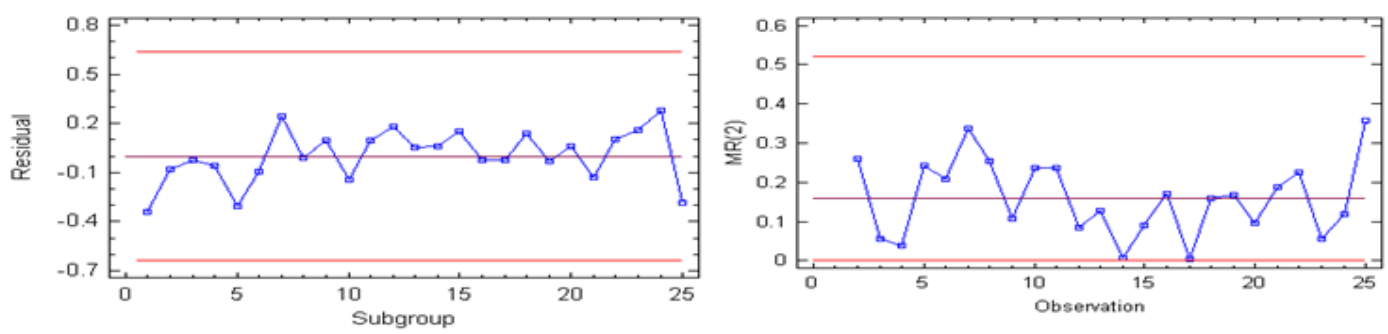

Figures $29 \& 30$. "ARIMA chart for speed" \& “MR(2) chart for speed residual".
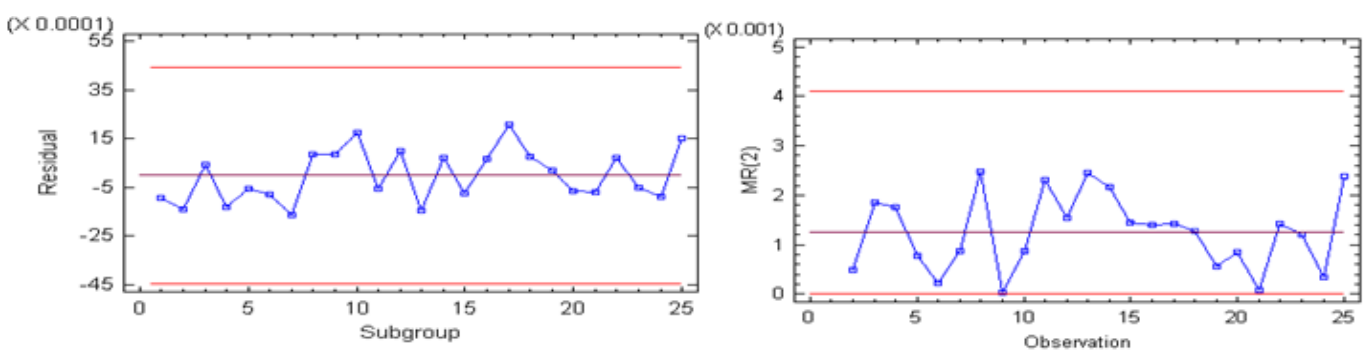

Figures $31 \&$ 32. "ARIMA chart for thickness" \& "MR(2) chart for thickness residual". 
The Trend chart

\section{Model I}

$$
\begin{array}{ll}
X-b a r=\frac{\sum X_{i}}{5} & \mathrm{i}=1 \text { to } 5 \text { for } 125 \text { observations } \\
X_{T}=867.919+0.140455 i & \mathrm{i}=1 \text { to } 125 \text { observations } \\
X-\text { bar }_{T}=\frac{\sum X_{T i}}{5} & \mathrm{i}=1 \text { to } 5 \text { for } 125 \text { observations }
\end{array}
$$

$$
\operatorname{Residual}(R)=X-b a r-X-b a r_{T}
$$

$$
M R=\left|R_{j}-R_{j-1}\right| \quad \quad \mathrm{j}=1 \text { to } 25 \text { subgroups }
$$

\begin{tabular}{|c|c|c|c|}
\hline \multicolumn{2}{|r|}{ Variables } & Model I & Model I I \\
\hline \multirow{5}{*}{$\begin{array}{l}\widehat{N} \frac{t}{\pi} \\
\frac{\sim}{\Sigma} \frac{5}{U}\end{array}$} & Period & $\# 1-25$ & $\# 1-25$ \\
\hline & UCL: +3.0 sigma & 4.95552 & 4.95266 \\
\hline & Centerline & 1.51671 & 1.51583 \\
\hline & LCL:-3.0 sigma & 0.0 & 0.0 \\
\hline & Out-of-control signals & 0 & 0 \\
\hline \multirow{4}{*}{ 它 } & Period & $\# 1-25$ & $\# 1-25$ \\
\hline & Process mean & 876.7676 & 876.768 \\
\hline & * Process sigma & 1.3446 & 1.34382 \\
\hline & Mean MR(2) & 1.51671 & 1.51583 \\
\hline
\end{tabular}

$$
\mathrm{LCL}=\mathrm{X}-\mathrm{bar}_{\mathrm{T}}-3(\overline{\mathrm{MR}} / 1.128)
$$

$$
\overline{\mathrm{MR}}=\frac{\sum M R}{24}
$$

$$
\mathrm{UCL}=\mathrm{X}-\mathrm{bar}_{\mathrm{T}}+3(\overline{\mathrm{MR}} / 1.128)
$$

\section{Model I I}

The model is provided by Applied Technology Company (www.e-AT-USA.com) for constructing Trend charts when a trend in the process is expected.

Table 6. "Trend charts parameters of force". 
The trend chart is designed to determine whether the process is in a state of statistical control or not. The trend control chart is used when a trend in the process is expected. X-bar, UCL, and LCL are constructed taking into consideration the linear regression line fit to all previous data to avoid any false alarms which may be resulted from the trend.
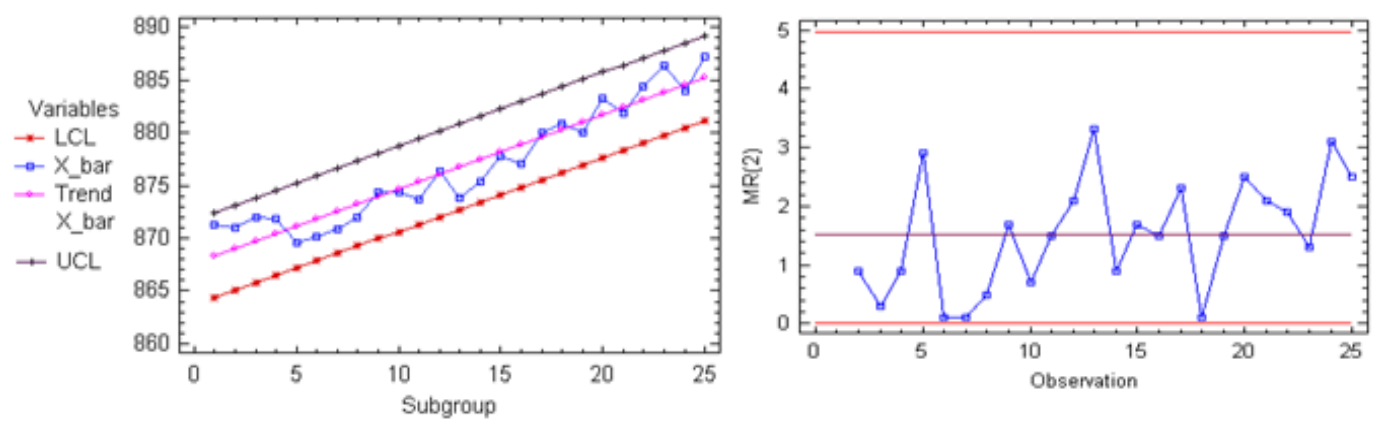

Figures $33 \& 34$. "Trend chart (Model I) for force" \& "MR(2) chart for force residual".
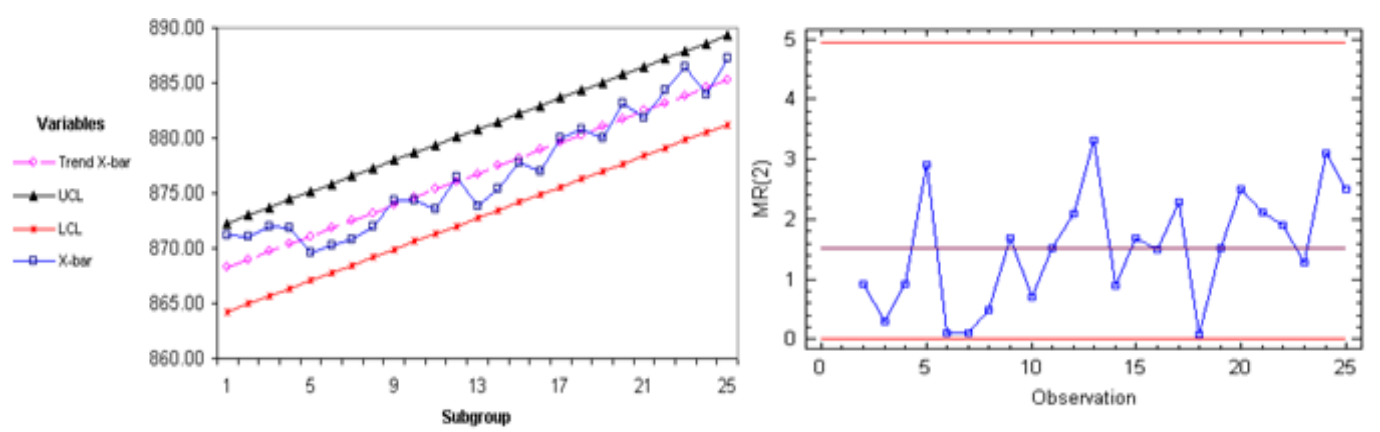

Figures $35 \& 36$. "Trend chart (Model II) for force" \& "MR(2) chart for force residual".

\subsection{The multiple variable analysis}

\begin{tabular}{|l|l|l|l|l|}
\hline \multirow{2}{*}{ Characteristics Variables } & Force & Speed & Thickness \\
\hline \multirow{3}{*}{ Force } & Correlation & & 0.2623 & 0.0705 \\
\cline { 2 - 5 } & Sample Size & & $(125)$ & $(125)$ \\
\cline { 2 - 5 } & P-Value & & 0.0031 & 0.4347 \\
\hline \multirow{4}{*}{ Speed } & Correlation & 0.2623 & & -0.0080 \\
\cline { 2 - 5 } & Sample Size & $(125)$ & & $(125)$ \\
\cline { 2 - 5 } & P-Value & 0.0031 & & 0.9290 \\
\hline \multirow{3}{*}{ Thickness } & Correlation & 0.0705 & -0.0080 & \\
\cline { 2 - 5 } & Sample Size & $(125)$ & $(125)$ & \\
\cline { 2 - 5 } & P-Value & 0.4347 & 0.9290 & \\
\hline
\end{tabular}

Table 7. "Correlation coefficients of force, speed, and thickness". 
Table 7 shows the Pearson product moment correlations between each pair of variables. These correlation coefficients range between -1 and +1 and measure the strength of the linear relationship between the variables.

\begin{tabular}{|c|c|c|c|c|}
\hline Force & $\begin{array}{l}8 \\
8 \\
8 \\
8 \\
8\end{array}$ & 8 & $\circ$ & 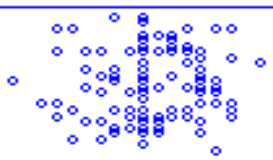 \\
\hline 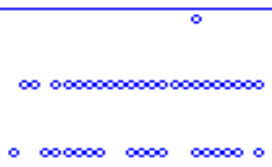 & & Speed & & $\begin{array}{c} \\
0.000000000000000 \\
0000000000000\end{array}$ \\
\hline 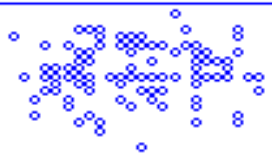 & $\begin{array}{l}8 \\
8 \\
8\end{array}$ & $\begin{array}{l}8 \\
8 \\
8 \\
8\end{array}$ & $\circ$ & Thickness \\
\hline
\end{tabular}

Figure 37. "Scatter plot for force, speed and thickness".

\subsection{Multivariate control charts}

\section{$\underline{\mathrm{T}^{2} \text { chart for the primary data }}$}

\begin{tabular}{|c|c|c|}
\hline \multicolumn{2}{|c|}{ Charts $\quad$ Variables } & Force, Speed and Thickness \\
\hline \multirow{4}{*}{$\begin{array}{l}\overline{8} \\
\frac{1}{0} \\
\frac{\pi}{5} \\
0 \\
0 \\
1 \\
1\end{array}$} & Alpha & 0.0027 \\
\hline & UCL & 14.8496 \\
\hline & LCL & 0.0 \\
\hline & Out-of-control signals & 15 above UCL \\
\hline \multirow{4}{*}{ 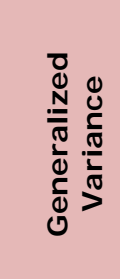 } & Alpha & 0.0027 \\
\hline & UCL & 0.0000803403 \\
\hline & LCL & 0.0 \\
\hline & Out-of-control signals & 0 \\
\hline
\end{tabular}

Table 8. " $\mathrm{T}^{2}$ and generalized variance charts parameters for primary data".

$\mathrm{T}^{2}$ control chart is constructed for the primary data of the three variables. Unlike most control charts which treat variables separately, this chart takes into account possible correlations between the variables. The control limits have been placed so as to give a $0.27 \%$ false alarm rate. 


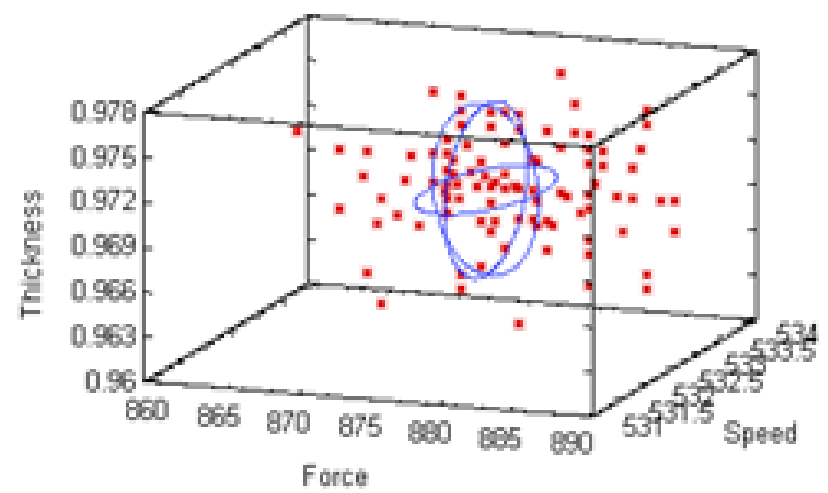

Figure 38. "Control ellipsoid for $\mathrm{T}^{2}$ chart for the primary data".
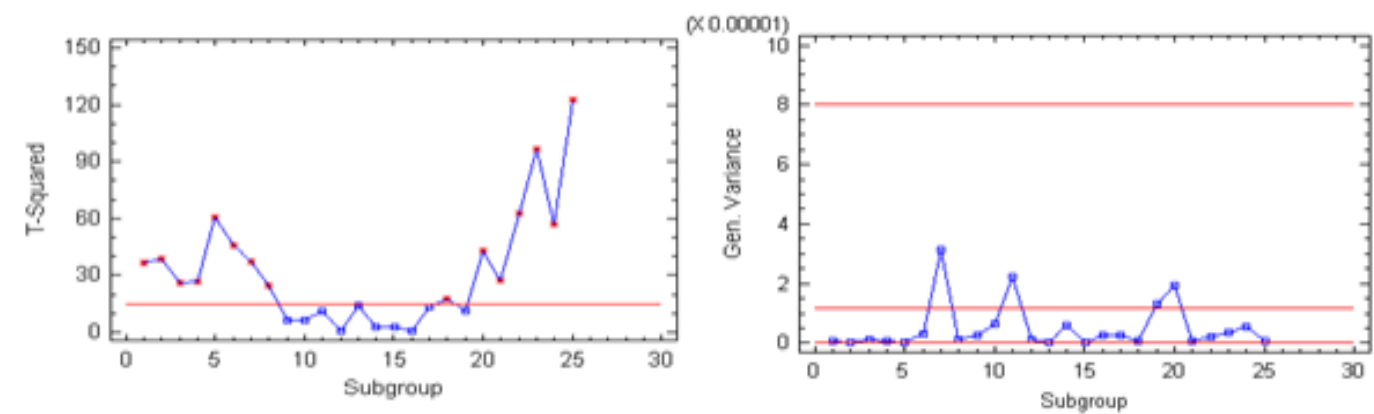

Figures $39 \& 40 . " \mathrm{~T}^{2}$ control chart for the primary data" \& "Generalized chart for the primary data".

\section{EWMA chart for the primary data}

\begin{tabular}{|c|c|c|}
\hline \multicolumn{2}{|c|}{ Charts $\quad$ Variables } & Force, Speed and Thickness \\
\hline \multirow{4}{*}{ 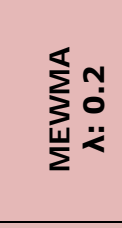 } & Alpha & 0.0027 \\
\hline & UCL & 3.39 \\
\hline & LCL & 0.0 \\
\hline & $\begin{array}{l}\text { Out-of-control } \\
\text { signals }\end{array}$ & 22 above $U C L$ \\
\hline \multirow{4}{*}{ 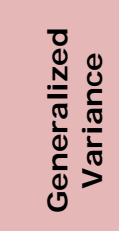 } & Alpha & 0.0027 \\
\hline & UCL & 0.0000803403 \\
\hline & LCL & 0.0 \\
\hline & $\begin{array}{l}\text { Out-of-control } \\
\text { signals }\end{array}$ & 0 \\
\hline
\end{tabular}

Table 9. "MEWMA and generalized variance charts parameters for primary data". 
MEWMA control chart is constructed for the primary data of the three variables. Unlike most control charts which treat variables separately, this chart takes into account possible correlations between the variables. The control limits have been placed so as to give a $0.27 \%$ false alarm rate.

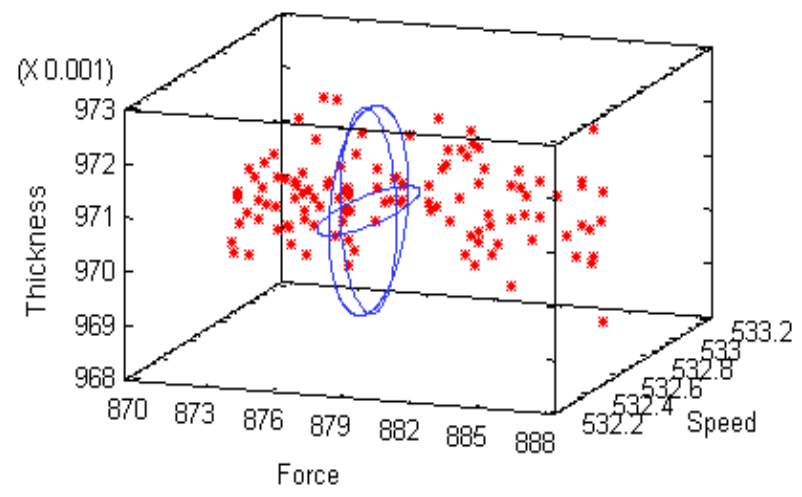

Figure 41. "Control ellipsoid for MEWMA chart for the primary data".
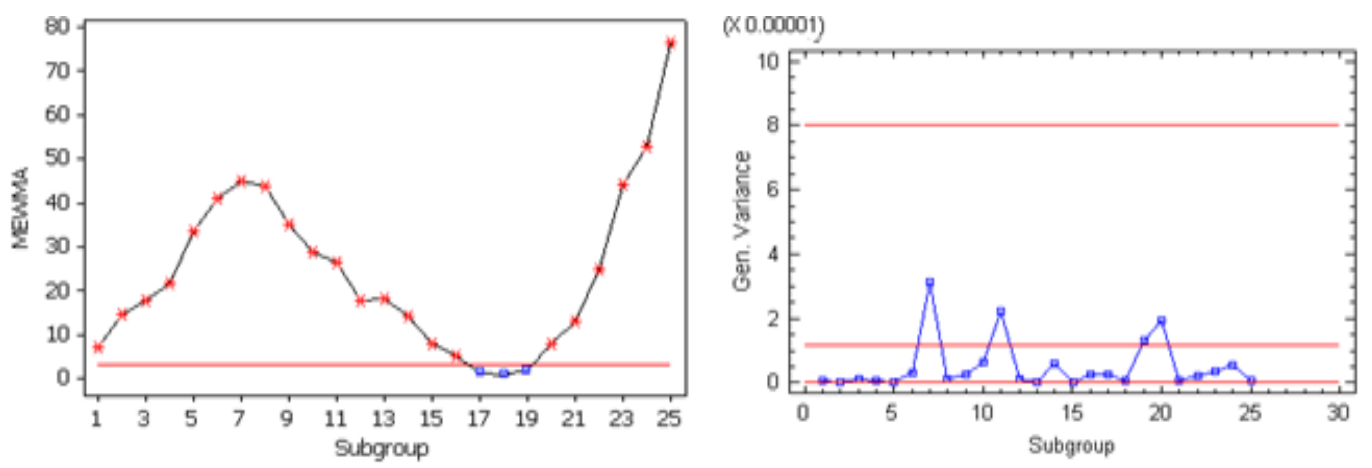

Figures $42 \& 43$. "MEWMA control chart for the primary data" \& "Generalized variance chart for the primary data".

\section{$\underline{\mathrm{T}^{2} \text { chart for the regressed data }}$}

$\mathrm{T}^{2}$ control chart is constructed for the regressed data of the three variables. Unlike most control charts which treat variables separately, this chart takes into account possible correlations between the variables. The control limits have been placed so as to give a $0.27 \%$ false alarm rate. 


\begin{tabular}{|c|c|c|}
\hline \multicolumn{2}{|c|}{$\begin{array}{ll}\text { Charts } & \text { Variables } \\
\end{array}$} & Force, Speed and Thickness \\
\hline \multirow{4}{*}{ 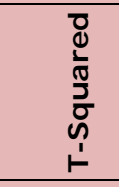 } & Alpha & 0.0027 \\
\hline & UCL & 14.8496 \\
\hline & LCL & 0.0 \\
\hline & $\begin{array}{l}\text { Out-of-control } \\
\text { signals }\end{array}$ & 0 \\
\hline \multirow{4}{*}{ 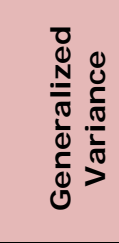 } & Alpha & 0.0027 \\
\hline & UCL & 0.0000522935 \\
\hline & LCL & 0.0 \\
\hline & $\begin{array}{l}\text { Out-of-control } \\
\text { signals }\end{array}$ & 0 \\
\hline
\end{tabular}

Table 10. " $\mathrm{T}^{2}$ and generalized variance charts parameters for regressed data".

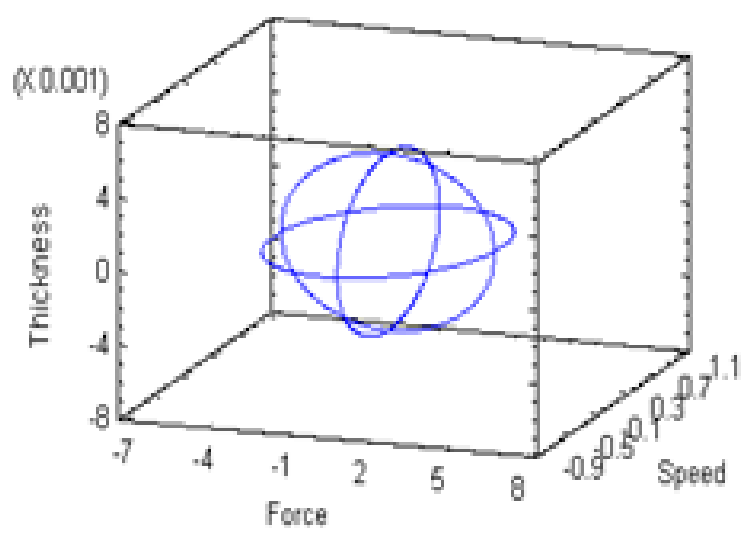

Figure 44. "Control ellipsoid for $\mathrm{T}^{2}$ chart for the regressed data".
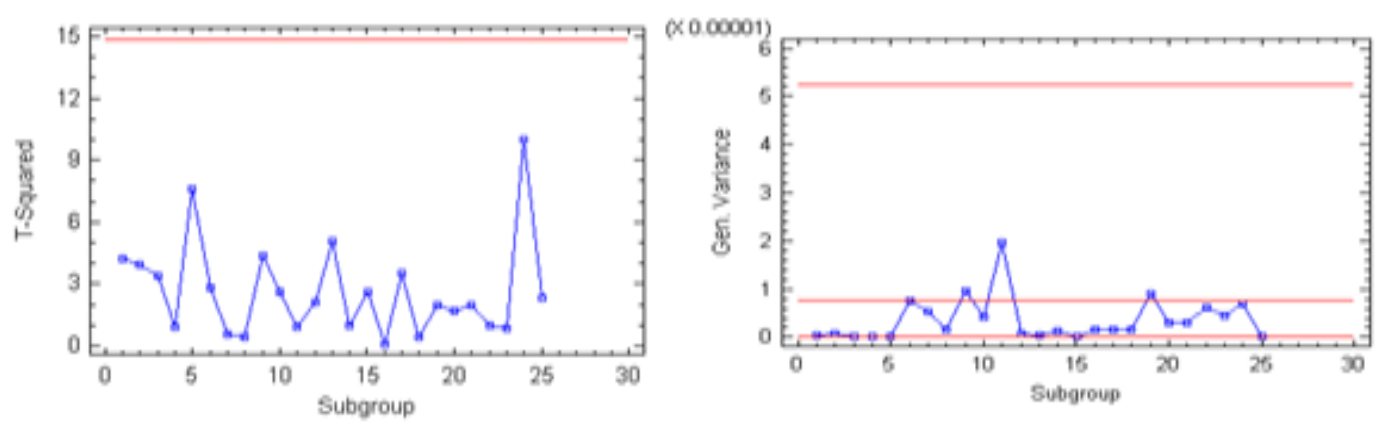

Figures $45 \& 46$. "T2 control chart for the regressed data" \& "Generalized variance chart for the regressed data".

Multivariate EWMA chart for the regressed data

MEWMA control chart is constructed for the regressed data of the three variables. Unlike most control charts which treat variables separately, this chart takes into 
account possible correlations between the variables. The control limits have been placed so as to give a $0.27 \%$ false alarm rate.

\begin{tabular}{|c|c|c|}
\hline \multicolumn{2}{|c|}{$\begin{array}{ll}\text { Charts } & \text { Variables } \\
\end{array}$} & \multirow{3}{*}{$\begin{array}{l}\text { Force, Speed and Thickness } \\
0.0027 \\
339\end{array}$} \\
\hline \multirow{4}{*}{ 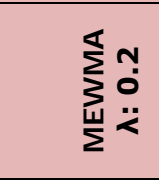 } & Alpha & \\
\hline & UCL & \\
\hline & LCL & 0.0 \\
\hline & $\begin{array}{l}\text { Out-of-control } \\
\text { signals }\end{array}$ & 0 \\
\hline \multirow{4}{*}{ 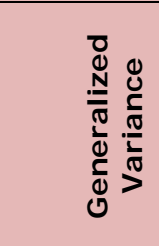 } & Alpha & 0.0027 \\
\hline & UCL & 0.0000522935 \\
\hline & LCL & 0.0 \\
\hline & $\begin{array}{l}\text { Out-of-control } \\
\text { signals }\end{array}$ & 0 \\
\hline
\end{tabular}

Table 11. "MEWMA and generalized variance charts parameters for regressed data".

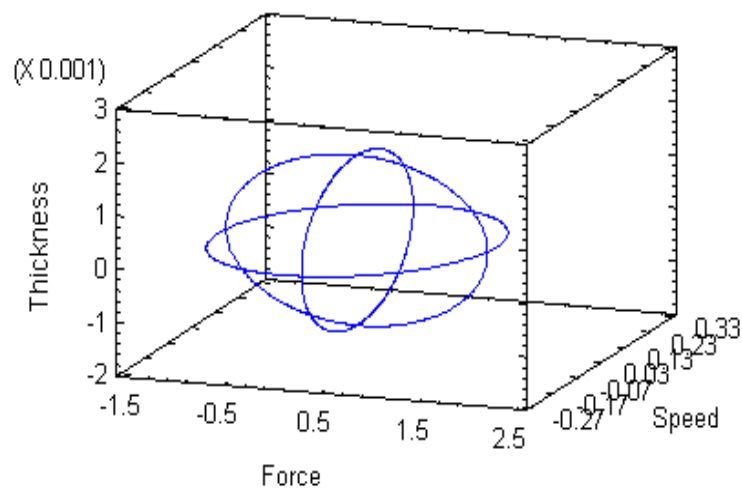

Figure 47. "Control ellipsoid for MEWMA chart for the regressed data".
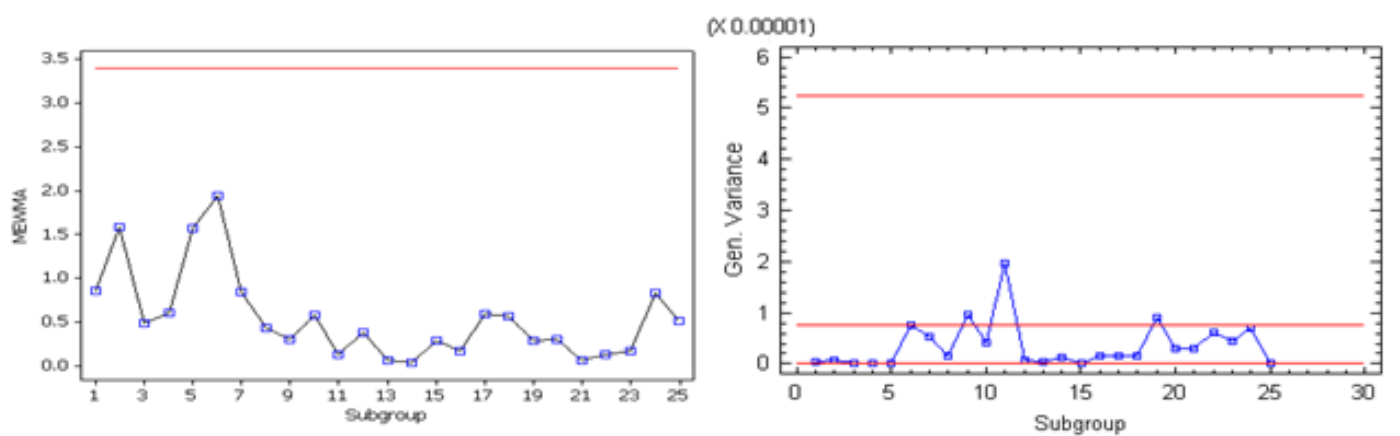

Figures $48 \& 49$. "MEWMA control chart for the regressed data" \& "Generalized variance chart for the regressed data".

\section{Results and discussions}

From the above analysis of control charts, the following results can be obtained: 


\section{Univariate control charts}

- The analysis indicates that the force data are autocorrelated, the data are not independent, as shown in Figure 8. This typically causes sigma to be underestimated and hence generates very narrow control limits. This is the reason why there are so any 'out-of-control' points on the EWMA chart (Figure 13). Consequently, the independence assumption is false, so we can't use EWMA control charts to assess process stability and we have to select another type of control procedures such as ARIMA chart (Figure 27) or Trend chart (Figures 33 and 35) to handle the non-independent data.

- Both ARIMA and Trend control charts work well in monitoring the stability of the force data, because they use the actual regression and the best fit of the data (see Figures 19 and 25).

- The analysis also indicates that both speed and thickness data are not autocorrelated, the data are independent, as shown in Figures 10 and 12 . As a result, the independence assumption is true, and we can use EWMA control charts (Figures 15 and 17 ) to monitor the stability of these variables.

- Both speed and thickness data are not autocorrelated, so ARIMA charts (Figures 29 and 31) will not be significantly better than EWMA charts in monitoring these data.

\section{Multivariate control charts}

- For the primary data, T2 and MEWMA control charts (Figures 39 and 42) show that the process is out-of-control. This is caused by the fact that both force and speed, as individual variables are 'out-of-control'.

- There is a weak correlation between speed and force (Table 7) with a small value $(r=0.26)$. So, the problems that we have seen in EWMA charts will not be fixed when the data are collected together in a multivariate chart. If there is chaos (i.e., lack of control) in input variables, then a multivariate chart will also be unstable unless the correlation between the input variables cancels out the instability when we aggregate them, which is unlikely. 
- For the primary data, T2 and MEWMA control chart are not good approaches to assess the process stability. However, they may be good choices if we could remove factors that are causing the force and speed variables to be unstable.

- For the regressed data, T2 and MEWMA control charts (Figures 45 and 48) are good techniques to assess the process stability because they take into consideration the nature and the fit of data (trend, autoregressive, exponential, etc.)

- The results of multivariate control charts illustrate the results of univariate control charts. The univariate control charts were not valid for monitoring the actual data while they were valid for monitoring the regressed data. The multivariate control charts were not valid for monitoring the actual data while they were valid for monitoring the regressed data.

Finally, the application study presents an optimum approach for investigating and adjusting quality control methodologies to monitor the manufacturing processes specially that are in a dynamic behavior mode such as rolling process. Hence, the required quality improvement can be obtained with the least costs and efforts if the appropriate corrective actions will be taken.

\section{Conclusions}

The dynamic behavior is often viewed as a disruption to the normal operation and performance of the manufacturing system. Because the control of dynamic behavior has been challenging and often elusive in practice, some industries use traditional statistical process control techniques which are not valid for monitoring the dynamic behavior. Others rely on experience and guesswork. Due to poor understanding and control of the dynamic behavior, large product and dollar loss often results. This paper presents an adjustment framework to advance the understanding and opportunities for improving the operations of dynamic behavior nature, which are difficult to be handled using traditional statistical process control methods because of the problems of the dynamic behavior such as temporal trend, non-normality and autocorrelation. Thus, this study provides a framework for statistical process control methods of such manufacturing process situations and develops techniques in order to improve their detection speed, sensitivity, and 
robustness. The cold rolling process was chosen as the practical application for our study because it provides a real environment for the development of dynamic behavior monitoring and adjustment procedures. Based on the results of this investigation, it can be concluded that:

- The run chart is an important tool for determining the effective zone of manufacturing processes that are in a dynamic behavior mode.

- An autocorrelation test should be applied as an initial step in any practical application in order to understand the nature of the data and to have a good background of the optimum approach for analyzing it.

o In absence of autocorrelation, the independence assumption is not violated and the traditional control charts (e.g., Shewhart charts) can be used for monitoring the manufacturing process and to assess its stability.

o In presence of autocorrelation, the independence assumption is violated and the traditional control charts (e.g., Shewhart charts) can't be used to assess process stability, and we have to select another type of control procedures (e.g., ARIMA charts) to handle the non-independent data.

- When the traditional control charts are invalid for monitoring a certain data set, regressed models (e.g., linear model, and ARIMA model) might be helpful in constructing a control chart (Trend chart, and ARIMA chart) that takes the regression and the fit of the data into consideration. In this case, the control chart reflects the actual behavior of the manufacturing process and corrects the false alarm rates.

- A correlation test should be a first step in multivariate process control in order to have a good understanding of the strength of the correlation between the variables and to know to what extent the multivariate monitoring is related to the individual monitoring of the variables.

- If there is chaos (i.e., lack of control) in the input variables, then a multivariate chart will also be unstable unless the correlation between the input variables cancels out the instability when we aggregate them. 
- The comparison between the univariate and the multivariate control charts indicates that they act as a compatible system for monitoring the manufacturing process. If the multivariate control chart detects a change, then the univariate control charts will be helpful in determining the characteristic, which caused this change.

- This paper lays a solid foundation for future research into statistical process control methods for manufacturing processes in order to improve their detection speed, sensitivity, and robustness. Advancement in these areas will improve quality as well as saving money and time.

\section{Future Work}

Design of experiments (DOE) techniques can be used to study the settings of the process and to determine which factors have the greatest impact on the resultant quality and to discard the factors with less effect on the process. Such a combination between DOE and quality control will result in increasing productivity and improving quality in any business.

Multi-objective optimization might be an effective technique when studying the quality control for a process of simultaneously two or more conflicting objectives which are subjected to certain constraints. That will be a good application of the combination between quality control and operations research.

In driving toward automation and computer integrated manufacturing ( $\mathrm{ClM}$ ), industries are constantly seeking effective tools to monitor and control increasingly complicated manufacturing processes. Neural Networks (NN) might be promising tools for on-line monitoring of complex manufacturing processes. Their superior learning and fault tolerance capabilities enable high success rates for monitoring the manufacturing processes with eliminating the need for explicit mathematical modeling.

Finally, we propose a simulation for quality control systems using a suitable software package such as ARENA. 


\section{References}

Aerne, L. A., Champ, C. W., \& Rigdon, S. E. (1991). Evaluation of Control Charts under Linear Trend. Communications in Statistics, 20, 334-3349.

Alt, F. B. (1985). Multivariate Quality Control. Encyclopedia of Statistical Sciences, 6, 110-122.

Alwan, L. C. (1992). Effects of Autocorrelation on Chart Performance. Communications in Statistics - Theory and Methodology, 21, 1025-1049.

Alwan, L. C., \& Roberts, H. V. (1988). Time Series Modeling for Statistical Process Control. Business and Economic Statistics, 6, 87-95.

Bissell, A. F. (1984). Estimating of Linear Trend from a Cusum Chart or Tabulation. Applied Statistics, 33, 152-157.

Blank, R. E. (1988). Multivariate X-bar and R Charting Techniques. Presented at the ASQC's Annual Quality Congress Transactions.

Box, G. E., \& Jenkins, G. M. (1970). Time Series Analysis: Forecasting and Control. San Francisco: Holden-Day, Oakland, CA.

Box, G. E., Jenkins, G. M., \& Reinsel, G. C. (1994). Time Series Analysis, Forecasting and Control. $3^{\text {rd }}$ Ed. Englewood Cliffs, NJ : Prentice-Hall.

Box, G. E., \& Kramer, T. (1992). Statistical Process Monitoring and Feedback Adjustment - A Discussion. Technometrics, 34, 251-257.

Box, G. E., \& Luceno, A. (1997). Statistical Control by Monitoring and Feedback Adjustment. New York: John Wiley \& Sons.

Coleman, D. E. (1997). Individual Contributions in "A Discussion on StatisticallyBased Process Monitoring and Control" edited by Montgomery, D.C. \& Woodall W.H. ,J ournal of Quality Technology 29, 148-149

Cook, D., \& Weisberg, S. (1982). Criticism and Influence Analysis in Regression. Sociological Methodology, 13, 313-361. 
Elsayed, B. A. (2000). Perspectives and Challenges for Research in Quality and Reliability Engineering. Production Research, 38, 1953-1976.

Farnum, N. R., \& Stanton L. W. (1989). Quantitative Forecasting Methods. Boston, MA: PWS-KENT Co.

Grant, E. L., \& Leavenworth, R. S. (1996). Statistical Quality Control, $7^{\text {th }}$ Ed. New York: McGraw-Hill, Inc.

Harris, T. J., \& Ross, W. H. (1991). Statistical Process Control Procedures for Correlated Observations. The Canadian Journal of Chemical Engineering, 69, 4857.

Hotelling, H. (1947). Multivariate Quality Control: Techniques of Statistical Analysis. New York: McGraw Hill.

Hunter, J. S. (1986). The Exponentially Weighted Moving Average. Quality Technology, 18, 203-210.

Jackson, J. E. (1956). Quality Control Methods for Two Related Variables. Industrial Quality Control, XII, 2-6.

Jackson, J. E. (1959). Quality Control Methods for Several Related Variables. Technometrics, 1, 359-377.

Lowry, C. A., Woodall, W. H., Champ, C. W., \& Rigdon, S. E. (1992). A Multivariate Exponentially Weighted Moving Average Control Chart. Technometrics, 34, 46-53.

Lu, C. W., \& Reynolds, J. M. (1999). EWMA Control Charts for Monitoring the Mean of Autocorrelated Processes. Quality Technology, 31, 166-187.

Martinich, J. S. (1997). Production and Operations Management. New York: John Wiley \& Sons, Inc.

Montgomery, D. C. (2005). Introduction to Statistical Quality Control, $5^{\text {th }}$ Ed. New York: John Wiley \& Sons.

Montgomery, D. C., \& Runger, G. C. (2003). Applied Statistics and Probability for Engineers, $3^{\text {rd }}$ Ed. New York: John Wiley $\&$ Sons. 
Montgomery, D. C., \& Wadsworth, H. M. (1972). Some Techniques for Multivariate Quality Control Applications. Presented at the ASQC's Annual Technical Conference Transactions. Washington, D. C.

Morrison, D. F. (1990). Multivariate statistical Methods, 3rd Ed. New York: McGrawHill, Inc.

Nembhard, H. B., \& Mastrangelo, C. M. (1998). Integrated Process Control for Startup Operations. J ournal of Quality Technology, 30, 201-211.

Nembhard, H. B., Mastrangelo, C. M., \& Kao, M. S. (2001). Statistical Monitoring Performance for Startup Operations in a Feedback Control System. Quality and Reliability Engineering International, 17, 379-390.

Ogunnaike, B. A., \& Ray, H. W. (1994). Process Dynamics, Modeling and Control. Oxford University Press, Oxford: McGraw-Hill, Inc.

Reed-Hill, R. A. (1994). Physical Metallurgy Principles, $3^{\text {rd }}$ Ed. Boston: PWS Publishing Company.

Roberts, S. W. (1959). Control Chart Tests Based on Geometric Moving Average. Technometrics, 1, 239-250.

Shewhart, W. A. (1931). Economic Control of Quality of Manufactured Product. New York: D. Van Nostrand Company.

Sultan, T. I. (1986). An Acceptance Chart for Raw Materials of Two Correlated Properties. Quality Assurance, 12, 70-72

VanBrackle, L. N., \& Reynolds, J. M. (1997). EWMA and CUSUM Control Charts in the Presence of Correlation. Communications in Statistics - Simulation, 26, 9791008.

(C) Journal of Industrial Engineering and Management, 2009 (www.jiem.org)

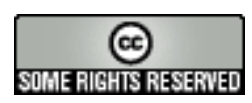

Article's contents are provided on a Attribution-Non Commercial 3.0 Creative commons license. Readers are allowed to copy, distribute and communicate article's contents, provided the author's and Journal of Industrial Engineering and Management's names are included. It must not be used for commercial purposes. To see the complete license contents, please visit http://creativecommons.org/licenses/by-nc/3.0/. 